\title{
Title: ETV7 limits antiviral gene expression and control of SARS-CoV-2 and influenza viruses
} \author{
Heaton $^{1, *}$ \\ ${ }^{1}$ Department of Molecular Genetics and Microbiology \\ Duke University School of Medicine \\ Durham, NC 27710, USA \\ *To whom correspondence should be addressed: \\ Nicholas S. Heaton, $\mathrm{PhD}$ \\ Assistant Professor \\ Department of Molecular Genetics and Microbiology (MGM) \\ Duke University Medical Center \\ 213 Research Drive, 426 CARL Building, Box 3054 \\ Durham, NC 27710 \\ Tel: 919-684-1351 \\ Fax: 919-684-2790 \\ Email: nicholas.heaton@duke.edu
}

Authors: Heather M. Froggatt ${ }^{1}$, Alfred T. Harding ${ }^{1}$, Brook E. Heaton ${ }^{1}$, and Nicholas S.

One Sentence Summary: ETV7 is an interferon-induced, repressive transcription factor that negatively regulates antiviral interferon-stimulated genes essential for controlling influenza virus and SARS-CoV-2 infections. 


\section{$1 \quad$ Abstract}

2 The type I interferon (IFN) response is an important component of the innate immune response to

3 viral infection. Precise control of interferon responses is critical; insufficient levels of interferon-

4 stimulated genes (ISGs) can lead to a failure to restrict viral spread while excessive ISG activation

5 can result in interferon-related pathologies. While both positive and negative regulatory factors

6 control the magnitude and duration of IFN signaling, it is also appreciated that a number of ISGs

7 regulate aspects of the interferon response themselves. However, the mechanisms underlying these

8 ISG regulatory networks remain incompletely defined. In this study, we performed a CRISPR

9 activation screen to identify new regulators of the type I IFN response. We identified ETS variant

10 transcription factor 7 (ETV7), a strongly induced ISG, as a protein that acts as a negative regulator

11 of the type I IFN response; however, ETV7 did not uniformly suppress ISG transcription. Instead,

12 ETV7 preferentially targeted a subset of known antiviral ISGs. Further, we showed the subset of

13 ETV7-modulated ISGs was particularly important for IFN-mediated control of some viruses

14 including influenza viruses and SARS-CoV-2. Together, our data assign a function for ETV7 as

15 an IFN response regulator and also identify ETV7 as a therapeutic target to increase innate

16 responses and potentiate the efficacy of interferon-based antiviral therapies. 
Introduction

19 The type I interferon (IFN) response is a transient innate immune defense system that, upon

20 activation by viral infection or therapeutic IFN treatment, induces the transcription of hundreds of

21 interferon-stimulated genes (ISGs) (1). Many ISGs have characterized antiviral roles that restrict

22 viral replication by either interfering with viral processes directly or altering cellular pathways

23 required for viral replication (2). However, because replication mechanisms and points of

24 interaction with the cell differ between viruses, individual ISGs have varying potencies against

25 different viruses (3-5). As a result, unique combinations of ISGs are thought to mediate successful

26 antiviral responses against distinct viruses $(1,6)$.

28 The canonical activation pathway of the type I IFN signaling pathway induced by viral infection,

29 or after therapeutic administration $(7)$, is well understood $(8,9)$. Extracellular IFN is bound by its

30 cognate plasma membrane-localized receptor (IFNAR1/2). Downstream effectors (JAK proteins)

31 are phosphorylated to then activate formation of the interferon-stimulated gene factor 3 (ISGF3)

32 complex. Finally, the ISGF3 complex of STAT1, STAT2, and IRF9 translocates to the nucleus $(8)$

33 and binds the interferon sensitive response element (ISRE), with the consensus DNA motif

34 GAAANNGAAA, to activate transcription of ISGs (10).

36 As infection is cleared and virally-derived innate immune activators become scarce, interferon

37 production is reduced and the interferon-stimulated gene response is downregulated. To facilitate

38 this return to cell homeostasis, IFN induced negative regulators, such as SOCS1 (11) and USP18

39 (12), act at multiple levels in the signaling pathway (13). Thus, negative regulators of IFN

40 responses are an important group of IFN-stimulated genes that control the duration of ISG

41 induction and activity. Antagonism of interferon response negative regulators has been proposed

42 as a mechanism to enhance host antiviral responses to clear infection, both alone and in conjunction 
with IFN treatment (14-16), and most recently during the COVID-19 pandemic (17). However, regulators working upstream of transcription impact ISGs indiscriminately, including suppression of the pro-inflammatory effectors, that when overabundant, can induce a cytokine storm; for example, agonists of an IFNAR-downregulating protein, S1PR1 (18), are proposed for use against pandemic influenza viruses (19) and SARS-CoV-2 (20) to instead limit excessive immune responses associated with interferon signaling. An ideal negative regulator of the IFN response for antiviral therapeutic targeting would enhance virus restricting ISGs specifically, without affecting pro-immune cytokines.

In addition to the upstream regulators that broadly activate or suppress IFN responses, there are interferon-induced transcriptional regulators that enhance, limit, or fine-tune ISG activity (21). Many ISGs themselves participate in innate immune signaling to amplify IFN and other proimmune responses (22). Activators also add complexity by inducing non-canonical IFN response pathways or specific groups of ISGs. Interferon responsive factors (IRFs) 1 and 7 are ISGs and transcription factors that activate subsets of ISGs $(23,24)$. Further, recent work has shown that ELF1 (E74-like ETS transcription factor) is induced by IFN and facilitates the expression of a group of genes not otherwise activated by the IFN response (25). Additional regulatory steps for ISGs, post-JAK/STAT signaling, likely exist to allow the cell to fine-tune its antiviral activity for an effective and appropriate response. While interferon-induced positive regulators of the IFN response are known to shape the complexity of ISG activation, reports of analogous roles for negative regulators remain conspicuously absent. negative regulation, we performed a CRISPR activation (CRISPRa) screen that selected for factors 
68 (ETS variant transcription factor 7) as a negative regulator of the type I IFN response with a role

69 in controlling the expression of specific ISGs. We further showed the ETV7-modulated ISGs are

70 important for control of some IFN-sensitive respiratory viruses. Together, these data demonstrate

71 ETV7 is a suppressive component of the complex ISG regulatory network that could be targeted

72 to enhance specific antiviral responses against influenza viruses and SARS-CoV-2 $(1,26)$.

\section{Results}

A CRISPR activation screen identifies ETV7 as a negative regulator of the type I IFN response.

In order to identify negative regulators of the type I IFN response, we developed a type I IFN response reporter that included seven copies of the consensus interferon sensitive response element (ISRE) ahead of a minimal CMV promoter controlling expression of sfGFP (Fig. 1A). To make our reporter temporally specific, sfGFP was fused to a mouse ornithine decarboxylase (MODC) protein degradation domain to decrease its half-life (27). We stably introduced this construct into the A549 lung epithelial cell line along with a dCAS9-VP64 fusion protein and a MS2-p65-HSF1 activator complex required for the SAM CRISPR activation (CRISPRa) system (28). After clonal selection, $99.8 \%$ of the A549-SAM-IFN response cells expressed GFP in response to type I IFN treatment (Fig. 1B and C).

To perform the screen, we took the A549-SAM-IFN response cell line and introduced a lentivirus library containing sgRNAs designed to activate every putative ORF in the human genome (28) (Fig. 1D). After 48 hours, half of the cells were collected to determine the transduction efficiency and the remaining cells were re-plated for IFN stimulation. At 72 hours post-sgRNA introduction, the cells were treated with IFN- $\alpha$ and collected for fluorescence-activated cell sorting (FACS). During sorting, we eliminated reporter-positive cells and collected only cells that were nonresponsive to IFN as this population should theoretically be overexpressing a negative 


\section{Figure 1}

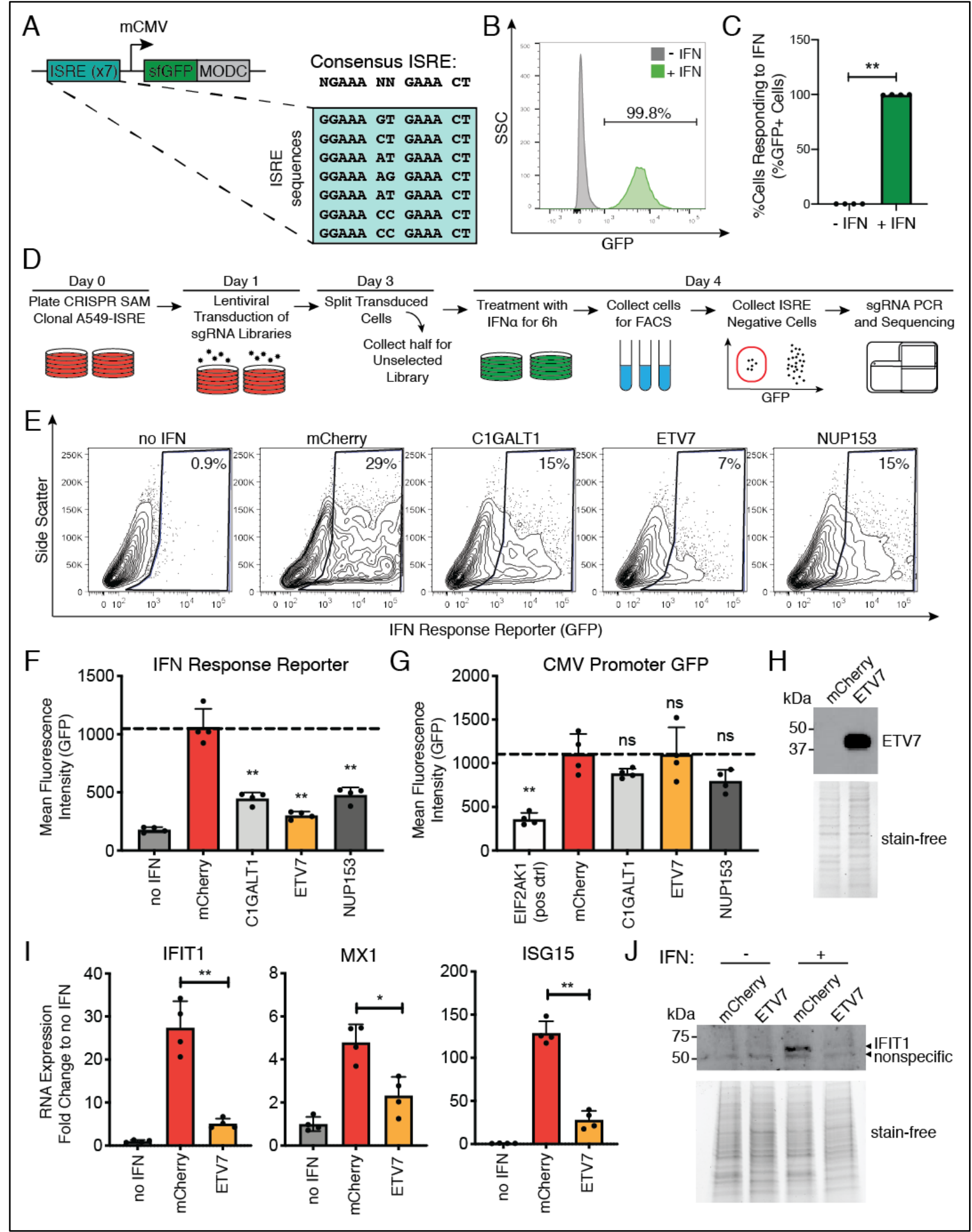

Fig. 1. A CRISPR activation screen identifies ETV7 as a negative regulator of the type I interferon response. (A) Diagram of the IFN response reporter used to identify cells responding to IFN. ISRE = interferon sensitive response element, MODC = protein degradation domain. (B) Flow cytometry histogram and (C) bar graph of A549-SAM-IFN response cells before and after IFN- $\alpha$ treatment $(1000 \mathrm{U} / \mathrm{mL}, 6 \mathrm{~h}$ ) (data shown as mean $\pm \mathrm{SD}, \mathrm{n}=4$, statistical analysis relative to 
Fig. 1. (continued) untreated control). (D) Diagram of CRISPRa screen workflow to identify negative regulators of the type I IFN response. (E) Flow cytometry plots of 293T cells transfected with the IFN response reporter and overexpression plasmids for the indicated screen hits and then treated with IFN- $\alpha(100 \mathrm{U} / \mathrm{mL}, 9 \mathrm{~h})$. (F) Quantification of $\mathbf{E}$ showing brightness of cells expressing GFP compared to the mCherry-expressing control (data shown as mean $\pm \mathrm{SD}, \mathrm{n}=4$ ). (G) Brightness of cells expressing GFP from a constitutively expressing plasmid in cells overexpressing the indicated genes (positive control $=\mathrm{EIF} 2 \mathrm{AK} 1 / \mathrm{HRI}$, shuts off translation) compared to control (data shown as mean $\pm \mathrm{SD}, \mathrm{n}=4)$. (H) Western blot showing ETV7 protein levels in 293T cells transfected with the ETV7 overexpression plasmid. Stain-free gel imaging was used to confirm equal loading. (I) Endogenous ISG mRNA expression levels measured using RT-qPCR after IFN$\alpha$ treatment $(100 \mathrm{U} / \mathrm{mL}, 9 \mathrm{~h})$ (data shown as mean $\pm \mathrm{SD}, \mathrm{n}=4)$. (J) Western blot comparing IFIT1 protein levels in control and ETV7 overexpressing cells after IFN- $\alpha$ treatment $(500 \mathrm{U} / \mathrm{mL}, 18 \mathrm{~h})$. Stain-free gel imaging was used to confirm equal loading. For all panels: P-values calculated using unpaired, two-tailed Student's t-tests $(* \mathrm{p}<0.05, * * \mathrm{p}<0.001)$ compared to mCherry-expressing control samples unless otherwise noted.

regulator of the IFN response. We performed two independent biological replicates of the screen and sequenced the sgRNA-containing amplicons derived from our input DNA, unselected transduced cells, and cells that were nonresponsive to type I IFN. Raw sequencing data was aligned, mapped, and subsequently analyzed using the MAGeCK pipeline (29) to generate z-score values for each gene. Genes were defined as "hits" if their z-scores exceeded two standard deviations from the mean, resulting in an overlap of 10 high-confidence genes between the two screen replicates (Fig. S1A, Table S1, Data files S1 and S2). We were seeking to identify regulators of the IFN response that are regulated by IFN themselves; therefore, we selected hits for validation previously reported to have at least a two-fold induction after IFN stimulation in the Interferome database (30). This analysis identified three hits (C1GALT1, ETV7, and NUP153) as potential negative regulators of the type I IFN response (Table S1). To validate our three hits, and to eliminate any potential off-target effects of CRISPRa, we cloned 107 the three ORFs and validated overexpression of the genes in 293 T cells (Fig. S1B). Co-transfection 108 of the overexpression plasmids and IFN response plasmid, followed by stimulation with IFN- $\alpha$, 109 resulted in lower reporter expression compared to a control mCherry-expressing plasmid (Fig. 1E 
110 and F, Fig. S1C). To verify this repressive activity was specific to the IFN response and the hits

111 were not general inhibitors of transcription or translation, we transfected the overexpression

112 plasmids along with a constitutively active GFP-expressing plasmid. We included a positive

113 control (EIF2AK1/HRI), which is known to suppress host translation when overexpressed (31).

114 None of the potential hits significantly reduced expression of the GFP-expressing plasmid (Fig.

115 1G, Fig. S1D). We therefore chose ETV7 for further characterization because: 1) NUP153 has

116 previously been shown to control the distribution of STAT1 in the cell (32), 2) ETV7 had not been

117 reported to play a role in the IFN response, and 3) it had the strongest inhibitory phenotype against

118 the IFN response reporter.

120 After confirming overexpression of ETV7 at the protein level (Fig. 1H), we verified that the

121 inhibitory effects of ETV7 were not restricted to the IFN response reporter plasmid. We collected

122 mRNA and protein from IFN- $\alpha$ stimulated ETV7 overexpression cells to quantify effects on the

123 expression of endogenous ISGs. ETV7 overexpression significantly repressed the induction of

124 three prototypical ISGs (IFIT1, MX1, and ISG15) at the RNA level (Fig. 1I). The reduction of

125 ISG expression during ETV7 overexpression was also demonstrated at the protein level for IFIT1

126 (Fig. 1J). These data together demonstrate that overexpression of ETV7 alone is sufficient to

127 repress ISG induction by type I IFN.

ETV7 acts as a transcription factor to repress IFN-induced expression.

130 ETV7 is known to be a repressive transcription factor $(33,34)$, although a role in repressing type

131 I IFN responses has never been reported. To determine whether ETV7 acts as a transcription factor

132 in this context, we generated a previously validated mutant of ETV7, called ETV7(KALK), which

133 is unable to bind DNA (Fig. 2A and B) (35). Overexpression of ETV7(KALK) and stimulation 
Figure 2

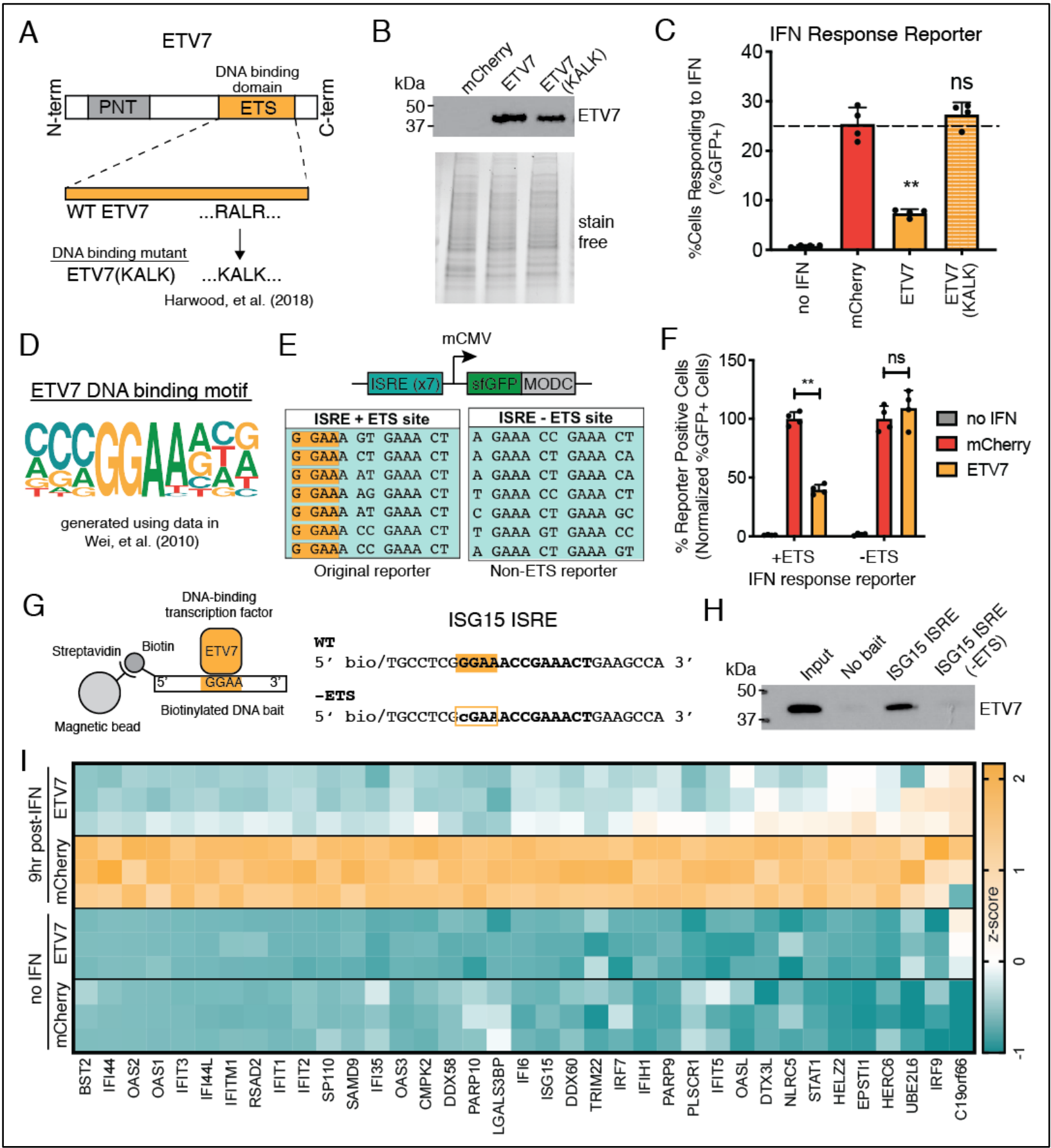

Fig. 2. ETV7 acts as a transcription factor to negatively regulate the type I IFN response. (A) Diagram showing the ETV7 protein domains and amino acid changes made to generate the DNA binding mutant, ETV7(KALK). (B) Western blot showing ETV7 protein levels in 293T cells transfected with WT or DNA binding mutant (KALK) ETV7 expression plasmids. Stain-free gel imaging was used to confirm equal loading. (C) Percent of 293T cells expressing GFP from the IFN response reporter with overexpression of WT or DNA binding mutant (KALK) ETV7 after IFN- $\alpha$ treatment $(100 \mathrm{U} / \mathrm{mL}, 9 \mathrm{~h}$ ) compared to control (data shown as mean $\pm \mathrm{SD}, \mathrm{n}=4)$. (D) ETV7's DNA binding position weighted matrix (PWM) generated using enoLOGOS (99) with data from Wei et al. (36). (E) Diagrams of the IFN response reporters containing (+ETS) and not containing (-ETS) potential ETV7 binding sites (ETS site, highlighted in yellow). (F) Normalized percent of 293T cells expressing GFP from IFN response reporters either containing or not 
Fig. 2. (continued) containing ETS sites after overexpression of ETV7 and IFN- $\alpha$ treatment (100 $\mathrm{U} / \mathrm{mL}, 6 \mathrm{~h}$ ) compared to mCherry-expressing control (data shown as mean $\pm \mathrm{SD}, \mathrm{n}=4)$. (G) Diagram of the DNA pull-down experiment using biotinylated DNA and streptavidin-coated magnetic beads to show binding of a transcription factor to a specific DNA sequence. Sequences of biotinylated DNA bait used to show binding of ETV7 to the WT ISG15 ISRE (93) and loss of binding with mutation of the ETS binding site (-ETS). (H) Western blot of DNA pull-down using biotinylated oligos containing the ISG15 ISRE sequence in its wild-type form (WT) or with a single nucleotide mutation (-ETS) to eliminate the ETS site, incubated with nuclear lysate from cells expressing ETV7 with IFN treatment $(100 \mathrm{U} / \mathrm{ml}, 9 \mathrm{~h})$. (I) Heat map displaying RNA levels of genes upregulated at least 2.5 -fold following IFN- $\alpha$ treatment $(100 \mathrm{U} / \mathrm{mL}, 9 \mathrm{~h})$ in control (mCherry) cells. Yellow $=$ upregulated, blue $=$ downregulated. For all panels: P-values calculated using unpaired, two-tailed Student's t-tests $(* \mathrm{p}<0.05, * * \mathrm{p}<0.001)$ relative to IFN-stimulated, mCherry-expressing control samples.

with IFN- $\alpha$ had no measurable effect on expression of the IFN response reporter, in contrast to WT ETV7 overexpression (Fig. 2C, Fig. S2A).

ETV7 has been reported to bind the canonical ETS family DNA motif, GGAA (36), known as an

“ETS” site (Fig. 2D). The original IFN response reporter design contained multiple ETS sites (Fig.

2E), which likely explains why it is negatively impacted by ETV7 in our screen. To test the

141 requirement of ETS sites for ETV7 repressive activity against our reporter, we generated an IFN

142 response reporter containing seven consensus ISREs from canonical ISGs that all lack ETS sites

143 (ISRE -ETS) (Fig. 2E). We transfected the two reporter plasmids (ISRE +ETS and ISRE -ETS)

144 independently into 293T cells and stimulated with IFN- $\alpha$. As expected, both reporter plasmids

145 responded to IFN treatment and were repressed by overexpression of known negative regulators

146 of the type I IFN response (SOCS1, USP18) that function upstream of transcription (Fig. S2B).

147 When ETV7 was transfected into cells with the IFN response reporters and stimulated with IFN

148 however, the repressive activity of ETV7 was restricted to the reporter plasmid containing ETS

149 motifs (Fig. 2F, Fig. S2C). 
151 To provide evidence of ETV7 directly binding ISRE motifs containing ETS sites, we performed a

152 DNA oligo-based pull-down experiment using the ISG15 ISRE sequence (Fig. 2G). We chose this

153 ISRE because 1) it contains an ETS binding site, 2) it was included in our initial IFN response

154 reporter, and 3) ETV7 was shown to impact ISG15 induction (Fig. 1I). In addition to the wild-

155 type ISG15 ISRE biotinylated oligos, we tested biotinylated oligos with a single nucleotide 156 mutation that eliminates the ETS site in the ISG15 ISRE (-ETS). We generated nuclear lysates

157 from 293T cells overexpressing ETV7 and treated with IFN- $\alpha$, incubated the lysate with either the

158 biotinylated WT or -ETS ISG15 ISRE oligos, and pulled down the biotinylated DNA using 159 streptavidin-coated magnetic beads. Western blotting for ETV7 protein revealed the transcription

160 factor bound the WT ISG15 ISRE containing the ETS site, but not the mutated version of the

161 promoter lacking the ETS site (Fig. 2H). Together, these experiments demonstrate that the

162 repressive activity of ETV7 requires both its ability to bind DNA and the presence of ETS sites in

163 the target ISG promoters.

ETV7 non-uniformly represses IFN-stimulated gene expression

166 Since consensus ISREs can either contain or lack a GGAA motif (Table S2), we hypothesized

167 ETV7 could differentially act on specific ISGs based on the presence or absence of ETS sites in

168 their ISRE sequences and promoters. To perform an unbiased examination of the effect of ETV7

169 upregulation, we performed RNA sequencing in cells with or without ETV7 overexpression and

170 IFN stimulation (Data file S3 and Fig. S2E). To identify the types of genes, processes, and

171 functions impacted by overexpression of ETV7, we generated lists of the most downregulated

172 genes during ETV7 overexpression, both before and after IFN treatment, and performed gene set

173 enrichment analyses. This analysis technique takes a gene list and returns overrepresented terms

174 from gene and protein databases (37). In the absence of IFN treatment, the most significantly

175 enriched terms were not biological pathways, but rather ETS family transcription factor binding 
motifs (Table S3); this is expected, as ETV7 is an ETS family member and the entire family binds

177 the same core motif, GGAA. In contrast, the genes specifically downregulated by ETV7 during

178 IFN treatment were highly enriched for processes and pathways associated with responses to

179 interferon and viral infection (Table S4). To visualize the effect of ETV7 upregulation specifically

180 on ISGs, we generated a heat map of the genes induced at least 2.5 -fold upon IFN treatment in our

181 RNA sequencing experiment (Fig. 2I). Consistent with our hypothesis, we found some genes were

182 suppressed by ETV7 overexpression more than others (Fig. 2I).

184 Although we had previously immunoprecipitated ETV7 with ISRE-containing oligos (Fig. 2H),

185 we next wanted to demonstrate ETV7 occupancy on native ISG promoters for genes targeted by ETV7 via chromatin immune-precipitation followed by quantitative PCR (ChIP-qPCR). To enable these experiments, we first generated a FLAG-tagged ETV7 (Fig. S2E) and demonstrated that the tag does not disrupt its ability to repress the IFN response reporter (Fig. S2F). We next selected the promoter of IFI44L for ChIP analysis as it was both highly affected by ETV7 and also harbors many ETS sites within ISRE-like sequences in its promoter (Fig. 2I and Fig. S2G and H). To

191 perform ChIP-qPCR, we generated sheared chromatin after cross-linking cells transfected with

192 FLAG-tagged ETV7 and treated with IFN- $\alpha$. We then performed immunoprecipitation using either 193 nonspecific IgG or anti-FLAG antibodies raised in mice or rabbits. After qPCR analysis, we found 194 no enrichment for a negative control region (the gene desert on chromosome 12) between the IgG and anti-FLAG samples (Fig. S2I). In contrast, DNA corresponding to the IFI44L promoter was

196 significantly enriched with both the rabbit and mouse anti-FLAG samples compared to the 197 nonspecific IgG samples (Fig. S2I). These experiments demonstrate that ETV7 acts as a 198 transcription factor to bind and suppress ISG promoters that containing GGAA motifs. 
ETV7 loss enhances antiviral IFN-stimulated gene expression.

202 Our experiments up to this point had primarily utilized overexpression of ETV7. One major

203 disadvantage of this approach is the non-physiological kinetics and magnitude of ETV7 expression

204 relative to what is observed after IFN stimulation in cells (Fig. 3A). To define the physiological

205 effects of ETV7 induction during the IFN response, we performed a series of loss-of-function

206 experiments. Our expectation was that the knockout of ETV7 would have the reciprocal effect on

207 IFN responses as protein overexpression (38). We transduced A549-IFN response reporter cells

208 (the original reporter with ISRE +ETS sites) with Cas9 and separately, two independent sgRNAs

209 targeting ETV7, KO1(sg16667) and KO2(sg16668), generated pooled lines using antibiotic

210 selection, and then stimulated with IFN- $\alpha$. Both guides resulted in significantly more IFN-induced

211 sfGFP expression compared to a control sgRNA (Fig. 3B, Fig. S3A).

213 We next generated clonal ETV7 knockout A549 lung epithelial cell lines (KO1-1, KO1-2) lacking

214 the reporter and sequenced the resulting DNA lesions to confirm ETV7 knockout. Since ETV7 is

215 normally only expressed after IFN stimulation, we treated with IFN- $\alpha$ and verified a reduction in

216 ETV7 expression at the RNA level, presumably via nonsense mediated RNA decay (Fig. 3C). A

217 representative housekeeping gene (ACTB) displayed no significant increases in transcription in

218 any of the ETV7 KO clones (Fig. 3D). We then selected twelve ISGs (IFITM1, RSAD2, OAS1-

219 3, IFIT1-3, IFI44L, ISG15, BST2, and IFI44) that were highly impacted by ETV7 in our RNA

220 sequencing results for RT-qPCR analysis after IFN treatment. Compared to clonal lines containing

221 a non-targeting guide, the ETV7 KO lines showed significant increases in induction of each of the

222 twelve ISGs (Fig. 3E-K, Fig. S3B-F). Thus, the physiological induction of ETV7 after IFN

223 stimulation affects the expression of ISGs. 
Figure 3

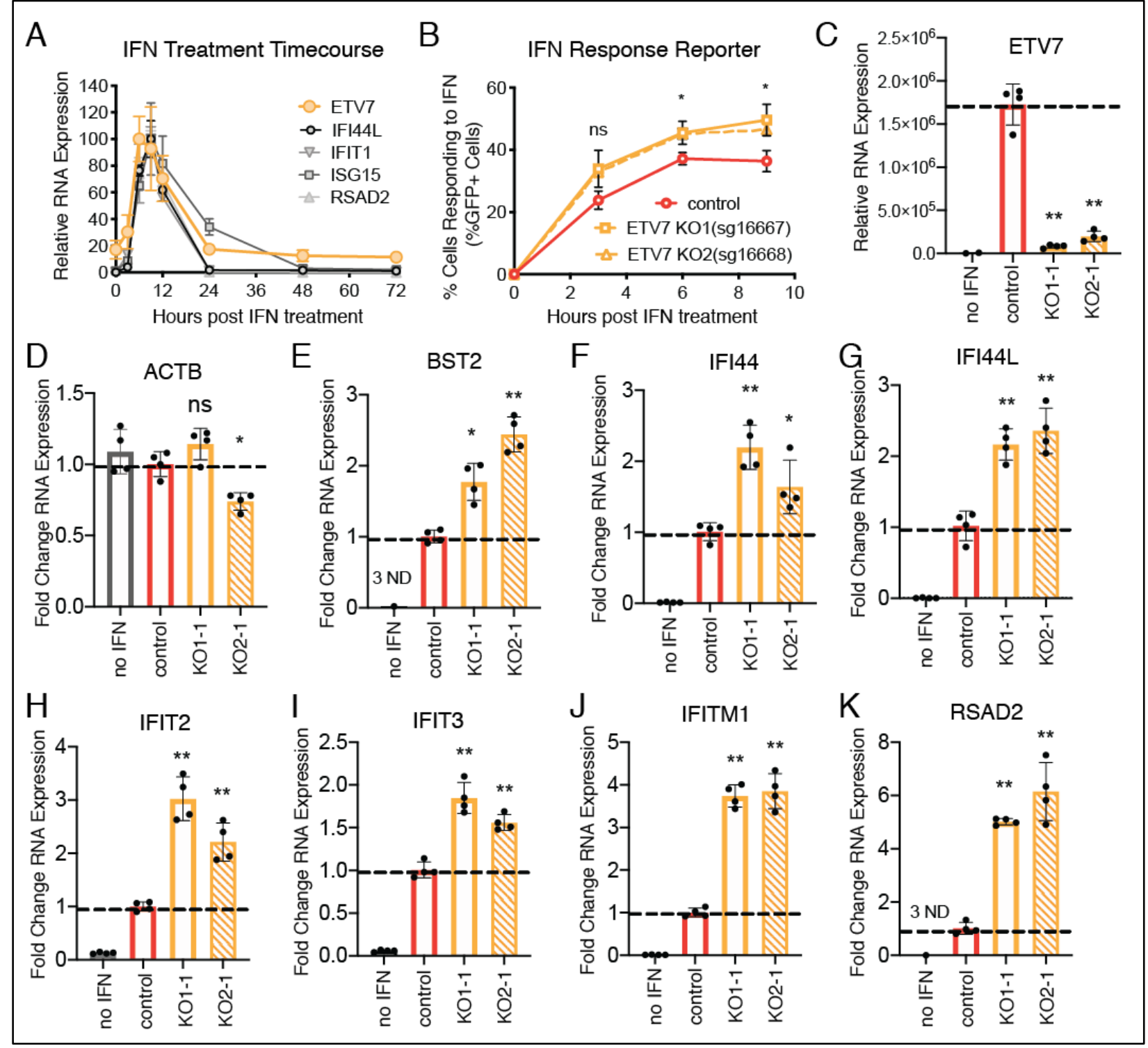

Fig. 3. Loss of ETV7 enhances expression of ISGs. (A) ETV7 and other ISG mRNA levels in A549 lung epithelial cells after IFN- $\alpha$ treatment $(100 \mathrm{U} / \mathrm{mL}, 6 \mathrm{~h})$ (data shown as mean $\pm \mathrm{SD}, \mathrm{n}=4$ ). (B) Percentage of cells expressing GFP from the IFN response reporter in two A549 ETV7 KO cell lines (pooled, 2 different guides) after IFN- $\alpha$ treatment $(1000 \mathrm{U} / \mathrm{mL}, 6 \mathrm{~h})$ compared to nontargeting control cells (data shown as mean $\pm \mathrm{SD}, \mathrm{n}=3$ ). (C) mRNA levels of ETV7 in nontargeting control and ETV7 KO A549 clonal cell lines after IFN- $\alpha$ treatment (1000 U/mL, 6 h) (data shown as mean $\pm \mathrm{SD}, \mathrm{n}=4)$. (D-K) mRNA levels of a housekeeping gene (D) and ISGs (E$K$ ) in control and ETV7 KO A549 clonal cell lines after IFN- $\alpha$ treatment $(100 \mathrm{U} / \mathrm{mL}, 9 \mathrm{~h})$ (data shown as mean $\pm \mathrm{SD}, \mathrm{n}=4$ ). For all panels: P-values calculated using unpaired, two-tailed Student's t-tests $\left({ }^{*} \mathrm{p}<0.05,{ }^{*} \mathrm{p}<0.001\right)$ compared to IFN-stimulated, non-targeting sgRNA control samples.

Suppression of ETV7 enhances IFN-mediated control of influenza viruses and SARS-CoV-2.

228 In trying to predict the physiological significance of excessive induction of these ETV7-regulated

229 ISGs during the type I IFN response, we noted that many have recognized antiviral functions $(2$, 
39, 40). To determine whether the effects of ETV7 suppression of ISG expression were relevant

231 in the context of a viral infection, we wanted to identify a virus restricted by the ISGs most affected

232 by ETV7 (41). Many of these genes with well-recognized antiviral functions (IFITM1, IFIT1-3,

233 OAS1-3, BST2, RSAD2) have been reported to play important roles in the restriction of influenza

234 viruses (42). IFITM1 has been shown to prevent viral entry (43), OAS proteins activate RNase L

235 to degrade viral RNA (44), IFITs bind viral RNA and promote antiviral signaling (45), and

236 BST2/Tetherin and RSAD2/Viperin restrict viral budding and egress $(46,47)$. Therefore, we

237 hypothesized that ETV7 dysregulation would affect influenza virus replication and spread.

We first infected our ETV7 KO A549 cells with a laboratory-adapted H1N1 influenza A virus (IAV), A/Puerto Rico/8/1934 (PR8). Using a hemagglutination (HA) assay to measure the number

241 of viral particles released over time, we observed reduced virus production in our ETV7 KO cells

242 compared to control cells (Fig. 4A). This was the anticipated outcome because loss of a negative

243 regulator (i.e. ETV7) is expected to enhance expression of antiviral ISGs. We also measured

244 infectious viral titers and found a significant reduction in our ETV7 KO cells compared to control

245 cells (Fig. S4A). Using a fluorescent reporter strain of PR8 (PR8-mNeon) (48), we next visualized

246 infection and spread. As expected, we observed fewer cells expressing mNeon in ETV7 KO cells

247 using both microscopy (Fig. 4B) and flow cytometry readouts (Fig. 4C). We also tested whether

248 this phenotype would extend to a more contemporary H1N1 IAV strain, A/California/07/2009

249 (Cal/09), as well as an unrelated Victoria lineage influenza B virus strain, B/Malaysia/2506/2004

250 (Mal/04) (49). Using fluorescent reporter strains of these viruses, we observed significant

251 decreases in the number of $\mathrm{Cal} / 09$ - and Mal/04-infected cells when comparing ETV7 KO cells to

252 control cells (Fig. 4D and E). In order to rule out non-IFN-related effects of ETV7 on inhibition

253 of influenza viral replication, we also performed these experiments with a non-influenza virus. We

254 selected Sendai virus $(\mathrm{SeV})$ because, although it is known to induce a strong IFN response, 


\section{Figure 4}

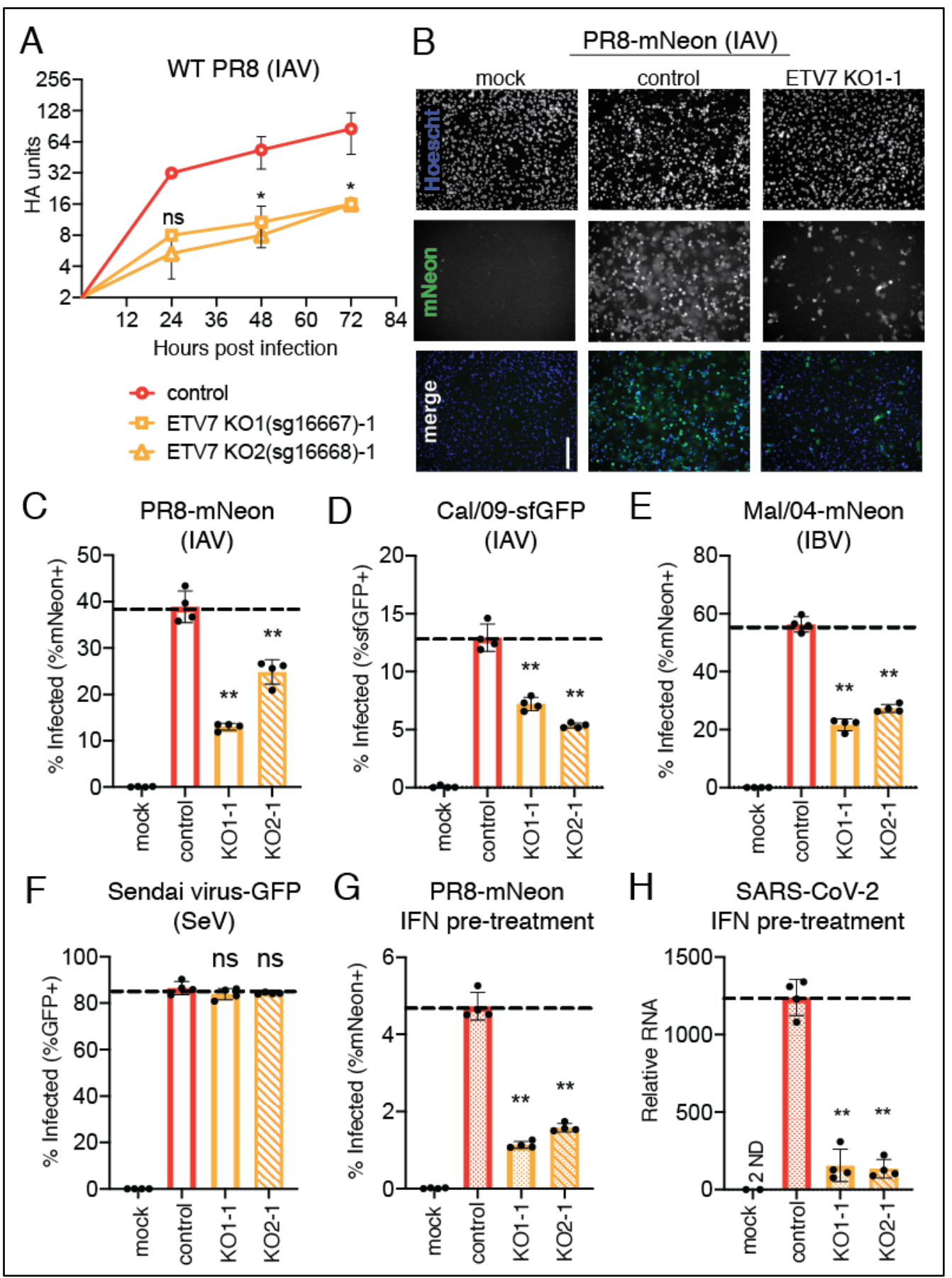

Fig. 4. Loss of ETV7 leads to restricted growth of multiple strains of influenza virus and SARS-CoV-2 with IFN treatment. (A) Hemagglutination (HA) assay of virus collected at indicated time points from non-targeting control and ETV7 KO A549 clonal cell lines after infection with WT PR8 virus (MOI=0.05, multicycle infection) (data shown as mean $\pm \mathrm{SD}, \mathrm{n}=3$ ). (B) Control and ETV7 KO A549 clonal cell lines after mock or PR8-mNeon reporter virus infection $(24 \mathrm{~h}, \mathrm{MOI}=0.1$, multicycle infection $)$. Green $=$ mNeon, blue $=$ nuclei. Scale bar, 200 $\mu \mathrm{m}$. (C) Flow cytometry quantification of control and ETV7 KO A549 clonal cell lines after infection with PR8-mNeon reporter virus $(24 \mathrm{~h}, \mathrm{MOI}=0.1$, multicycle infection) (data shown as mean \pm SD, n=4). (D, E) Percentage of infected (reporter+) cells from ETV7 KO A549 clonal cell lines compared to a control cell line after infection with (D) Cal/09-sfGFP or (E) Mal/04-mNeon 
Fig. 4. (continued) reporter viruses ( $24 \mathrm{~h}$, multicycle infection) (data shown as mean $\pm \mathrm{SD}, \mathrm{n}=4$ ). (F) Percentage of infected (reporter+) cells from ETV7 KO A549 clonal cell lines compared to a control cell line after infection with Sendai-GFP reporter virus $(24 \mathrm{~h})$ (data shown as mean $\pm \mathrm{SD}$, $\mathrm{n}=4)$. (G) Percentage of infected (reporter + ) cells from ETV7 KO A549 clonal cell lines compared to a control cell line after pre-treatment with IFN- $\alpha(100 \mathrm{U} / \mathrm{ml}, 6 \mathrm{~h})$ then infection with PR8mNeon reporter virus ( $24 \mathrm{~h}, \mathrm{MOI}=0.1$, multicycle) (data shown as mean $\pm \mathrm{SD}, \mathrm{n}=4)$. (H) $\mathrm{qPCR}$ detecting SARS-CoV-2 N vRNA in infected cells from ETV7 KO A549 clonal cell lines compared to a control cell line after pre-treatment with IFN- $\alpha(1000 \mathrm{U} / \mathrm{ml}, 6 \mathrm{~h})$ then infection with SARS$\mathrm{CoV}-2$ virus $(24 \mathrm{~h}, \mathrm{MOI}=0.1)$ (data shown as mean $\pm \mathrm{SD}, \mathrm{n}=4)$. For all panels: $\mathrm{P}$-values calculated using unpaired, two-tailed Student's t-tests $(* p<0.05, * * p<0.001)$ compared to infected, nontargeting sgRNA control samples.

previous reports (50) show SeV replication is relatively unaffected by type I IFN. Furthermore, many of the ISGs most impacted by ETV7 have little to no effect against SeV, including IFITM1 (51), IFIT1 (52), and BST2/Tetherin (53). Using of a fluorescent reporter SeV, we observed no significant change in the number of infected cells when comparing ETV7 KO cells to control cells

(Fig. 4F).

In addition to physiological induction of IFN after infection, exogenous IFN treatment is frequently utilized or proposed as an antiviral therapy (7), either when there is difficulty developing targeted antivirals (e.g. hepatitis C virus (54)) or there is an unexpected emergence of 265 a viral pathogen (e.g. swine or highly pathogenic avian influenza viruses (55), SARS-CoV (56),

266 Ebola virus (57), SARS-CoV-2 (58-60)). Therefore, we wanted to assess whether suppressing 267 ETV7 could be an effective strategy to enhance the antiviral effects of therapeutic IFN 268 administration. In support of this idea, we found treatment of ETV7 KO cells with IFN- $\alpha$ prior to 269 infection with PR8-mNeon led to an additional 5-fold enhancement of viral restriction compared 270 to IFN-treated WT control cells (Fig. 4G). Finally, since recent reports indicate that although 271 SARS-CoV-2 infections fail to induce a strong IFN responses (61-63), the virus is susceptible to 272 IFN treatment (64-66), we wanted to test if loss of ETV7 would potentiate IFN-mediated 273 suppression of SARS-CoV-2. With the same experimental design as the influenza virus 
experiment, we found that pre-treatment of ETV7 KO cells with IFN- $\alpha$ resulted in a further 10-

fold reduction in SARS-CoV-2 vRNA compared to IFN-treated control cells (Fig. 4H). This enhanced control was likely mediated via the ISG LY6E, which potently restricts SARS-CoV-2 (67, 68) and we found to be regulated by ETV7 (Fig. S4B). Together, these experiments demonstrate the potential of targeting ETV7 to enhance either the physiological or therapeutic effects of IFN to control viral infection.

\section{Discussion}

282 In this study, we performed a CRISPR activation screen to identify negative regulators of the type

283 I IFN response. Specifically, we were interested in negative regulators that contribute to the types

284 of differentiated ISG profiles that are essential for effective control of viral infections. From this 285 screen, we identified ETV7 as a negative IFN regulator and subsequently showed it acts as a transcription factor to repress subsets of ISGs through its recognized DNA binding motif. We also

287 demonstrated that the regulatory activity of ETV7 impacts the replication and spread of multiple strains of influenza viruses. ETV7 loss also increased the antiviral effects of exogenous interferon treatment against an H1N1 influenza virus and SARS-CoV-2. These findings demonstrate the

290 importance of ETV7 in fine-tuning the IFN response through specificity and transcriptional 291 repression to regulate antiviral ISG targets, and its potential as a target to enhance antiviral IFN292 based therapeutics.

ETV7 is a member of the ETS family of transcription factors. This family performs diverse 295 functions despite recognizing the same core DNA sequence, GGAA. Because these factors share 296 the same core motif, specificities are gained in other ways such as expression patterns (cell type, 297 basal expression, or immune pathway induction), active or repressive activity, and potential 298 binding partners $(69,70)$. ETV7 is induced as an ISG and is repressive, whereas most ETS 
transcription factors are activators, including ETS transcription factors recognized to assist in the induction of ISG expression (e.g. ELF1 (25), PU.1 (71)). We also found repeatedly in our work

301 that the reporters and genes impacted by ETV7 contained ETS sites within ISRE sequences (Fig.

302 2E-H, S2G-I, S4B). This is not unexpected because it is recognized that many ETS family 303 members bind extended motifs similar to ISREs called ETS-IRF composite elements (EICE) (72).

304 EICE-associated activity is reported to require an IRF binding partner to direct ETS transcription 305 factor activity $(71,73)$; therefore, it is likely ETV7 has an IRF binding partner. If ETV7 does 306 require a binding partner, this protein's induction and distribution likely contribute to the timing, 307 gene targets, and activity of ETV7 during the IFN response. It is known that IRFs can be basally 308 expressed (IRF2, IRF3), IFN-induced (IRF1, IRF7), or IFN-responsive (IRF9) (72), and the 309 availability of a binding partner could dramatically affect the timing and magnitude of effects on 310 EICE-controlled ISGs. Future work will define if ETV7 has specific binding partners and how 311 those interactions may contribute to the nonuniform, repressive activity of ETV7 during the type 312 I IFN response reported in this study.

314 IFN-induced regulators control the magnitude and duration of IFN responses in addition to the 315 temporal regulation of specific waves of ISGs (74). These coordinated waves of ISG induction can 316 peak early or late during the IFN response and are thought to correspond to specific stages of virus 317 replication or immune processes $(1,6)$. We compared the induction of ETV7 with IFI44L, IFIT1, 318 ISG15 and RSAD2, and we observed ETV7 is upregulated at earlier time points than these 319 prototypical ISGs (Fig. 3A). We expanded our analysis to published datasets of human gene 320 expression during respiratory infections and concluded that ETV7 is generally induced earlier than 321 many ISGs (75). Although not the focus of our study, ETV7's early induction pattern suggests it 322 may be a key regulator of the first stages of IFN-mediated gene induction. We favor a model 
323 wherein early ETV7 expression is responsible for reducing the accumulation, or delaying the 324 expression, of ISGs controlled by ISREs and promoters containing ETS motifs.

326 ETV7 is induced during infections across many vertebrate species $(76,77)$, indicating a potential 327 conserved, relevant role in the immune response; however, ETV7 has been lost in mice and closely 328 related rodents (78). Since mice and rodents have an intact interferon response pathway, a natural 329 question is: how are the activities of ETV7 being accounted for in these animals? While we have

330 no clear answer from the data in this study, it is well-recognized that IFN responses contain many 331 redundancies (41). Accordingly, we believe other ETS family members, potentially the closely 332 related ETV6 (which is also induced by IFNs), may perform the role of ETV7 in mice (79). Future 333 studies will be required to test the hypothesis that mice induce an ETV7-related alternative during 334 the type I IFN response.

336 Another important question is why the IFN-induced activity of ETV7 has been maintained 337 throughout evolution. In this report, we provide evidence that ETV7's activity reduces a cell's 338 ability to restrict virus infection; this seems counterintuitive to ETV7 benefitting the host. We 339 hypothesize that regulators like ETV7 are important to prevent excessive inflammatory signaling. 340 It is appreciated that negative regulators of the IFN response are required to prevent extreme and 341 prolonged immune responses, which are associated with poor disease outcomes after infection 342 (80-82). ETV7 potentially contributes to the cumulative activities of negative IFN regulators to 343 limit IFN responses during pathogen clearance. Additionally, it stands to reason that individual 344 ISGs have different toxic effects on the cell. It is tempting to speculate that ETV7 suppresses ISGs 345 whose accumulation is particularly harmful to cell viability and host recovery after infection. 
347 Additionally, the relevance of controlled IFN responses goes beyond infectious disease; patients

348 with dysfunctional USP18, a negative regulator of the IFN response, develop a type I

349 interferonopathy that results in a severe pseudo-TORCH (Toxoplasmosis, Other agents, Rubella,

350 Cytomegalovirus, and Herpes simplex) syndrome (83). Mouse knockouts for other negative

351 regulators of the IFN response (SOCS1, SOCS3, USP18) also develop non-pathogen associated,

352 chronic inflammatory diseases (84-87). ETV7's lack of a murine homolog eliminates an easily

353 generated animal knockout model to experimentally show ETV7's relevance as a general innate

354 immune repressor. However, genome-wide association studies (GWAS) have linked ETV7 to

355 autoimmune diseases including rheumatoid arthritis and multiple sclerosis $(88,89)$; both of these

356 autoimmune diseases have evidence of enhanced ISG expression $(90,91)$. Thus, although the

357 specific contributions of ETV7 activity to IFN regulation are currently undefined, its potential role

358 is not limited to viral infections.

360 In conclusion, this study identified ETV7 as a negative regulator of the type I IFN response.

361 Previously, ETV7 was appreciated to be an ISG; however, a specific function during the IFN

362 response was unknown. We determined that ETV7 acts as a transcription factor to target specific

363 ISGs for repression, potentially contributing to the complex ISG transcriptional landscape.

364 Additionally, many of the ETV7-regulated ISGs restrict respiratory viruses $(42,67,68)$, and we

365 showed that loss of ETV7 can further enhance the ability of type I IFN to control influenza virus

366 and SARS-CoV-2 replication. Further work is required to understand the complexity of IFN

367 regulation, while therapeutic targeting of factors like ETV7 could lead to the development of a

368 new class of host-directed antivirals that can enhance or tailor ISG responses to specific viruses. 


\section{Materials and Methods}

Cloning

371 To generate reporters sensitive to IFN, we designed gBlocks (IDT) containing ISREs to be cloned

372 into the pTRIP vector ahead of a minimal CMV promoter controlling expression of sfGFP. To

373 clone and express the open reading frames (ORFs) of our screen hits, we designed primers for 374 cloning into the pLEX-MCS vector using Gibson Assembly (NEB). To amplify ETV7, NUP153 375 and USP18 we used cDNA templates from Transomic Technologies. To amplify C1GALT1 and 376 EIF2AK1 we used RNA from IFN-stimulated A549 cells. The DNA binding mutant ETV7, 377 ETV7(KALK) (35), and codon-optimized SOCS1 expression plasmids were generated using a 378 gBlock (IDT). FLAG-tagged ETV7, ETV7(FLAG), was generated using a primer including the 379 FLAG tag. Non-targeting and ETV7-targeting CRISPR KO sgRNAs were cloned by annealing 380 oligos encoding the desired sgRNA sequence and ligating them directly into the lentiCRISPRv2 381 vector (Addgene). DNA was transformed into NEB 5-alpha high efficiency competent cells. Insert 382 size was verified with PCR and purified plasmids were sequenced using Sanger sequencing.

Cells

All cells were obtained from ATCC and grown at $37^{\circ} \mathrm{C}$ in $5 \% \mathrm{CO}_{2}$. A549 and $293 \mathrm{~T}$ cells were grown in Dulbecco's Modified Eagle Medium (DMEM) supplemented with 5\% fetal bovine serum, GlutaMAX, and penicillin-streptomycin. Madin-Darby canine kidney (MDCK) cells were 388 grown in minimal essential media (MEM) supplemented with 5\% fetal bovine serum, HEPES, $\mathrm{NaHCO}_{3}$, GlutaMAX, and penicillin-streptomycin. The A549 CRISPR-SAM cells were 390 previously validated (92) and transduced with the IFN response reporter three times before being 391 clonally selected. The A549 CRISPR KO cells were transduced (ETV7 KO1 = sg16667, ETV7 $392 \mathrm{KO} 2=\mathrm{sg} 16668$, nontargeting control $)$ and then selected using puromycin $(10 \mu \mathrm{g} / \mathrm{mL})$. A549-IFN 393 response reporter ETV7 KO lines were selected with puromycin and used as pooled lines. A549 
ETV7 KO lines were selected with puromycin and subsequently plated at a dilution to isolate

dashes, exonic sequences $=$ uppercase, intronic sequences $=$ lowercase.

ETV7 KO guide 1 ( $\operatorname{sg} 16667)$

WT 5' CTG CCA TGC protein length $=342 \mathrm{aa}$

KO1-1 allele 1 5' CTG CCA TGC ACC GCG GAA GCA CGG GTT CGA GAT GAA CGG ACG CGC 3' predicted protein length $=104 \mathrm{aa}$

KO1-1 allele 2 5' CTG CCA TGC ACC GCG GAA GCA CGG GTT CGA GAT GAA CGG ACG CGC 3' predicted protein length $=104 a \mathrm{a}$

KO1-2 allele 1 5' CTG CCA TGC ACC GCG GAA GCA CGG GTT CGA GAT GAA CGG ACG CGC 3'

predicted protein length $=104 \mathrm{aa}$

KO1-2 allele 2 5' CTG CCA TGC ACC GCG GAA GCA CGG GTT CGA GAT GAA CGG ACG CGC 3' predicted protein length $=104 \mathrm{aa}$

ETV7 KO guide $2(\operatorname{sg} 16668)$

WT 5' GCG ATG CCG CAG GCC CCC ATT GAC GGC AGG ATC GCT Ggtgagtgggagg 3’ protein length $=342 \mathrm{aa}$

KO2-1 allele 1 5' GCG ATG CCG CAG GCC CCC ATT GAC G-- --- --- -CT Ggtgagtgggagg 3' predicted protein length $=333$ aa

KO2-1 allele 2 5' GCG ATG CCG CAG GCC CCC ATT GAC GGC AGG --- --- --tgagtgggagg 3' predicted protein length $=$ unknown, loss of splice site

KO2-2 allele 1 5' GCG ATG CCG CAG GCC CCC ATT GAC G-- --- --- -CT Ggtgagtgggagg 3' predicted protein length $=333$ aa

KO2-2 allele 2 5' GCG ATG CCG CAG GCC CCC ATT GAC GGC AGG -TGA CGC TGgtgagtgggagg 3’ predicted protein length $=220 \mathrm{aa}$

$429 \quad$ Flow Cytometry

430 Cells were trypsinized and analyzed on a Fortessa X-20 (BD) machine with standard laser and

431 filter combinations. Data was visualized and processed with FlowJo software. 
434 The sgRNA library was packaged into lentivirus as previously described (92). After packaging 435 and titering the lentivirus, $2 \times 10^{8}$ A549-CRISPR-SAM-IFN response reporter cells were seeded

436 onto $15 \mathrm{~cm}$ plates (10 plates total). The next day they were transduced with the packaged $\operatorname{sgRNA}$

437 library $(\mathrm{MOI}=0.5)$. After $48 \mathrm{~h}$, the transduced cells were split and half were collected as a 438 transduction control, while the remaining half were plated back onto $15 \mathrm{~cm}$ plates. The next day, 439 cells were treated with IFN- $\alpha\left(4 \times 10^{3} \mathrm{U} / \mathrm{mL}\right)$ for $6 \mathrm{~h}$. Cells were then collected and sorted on a 440 Beckman Coulter Astrios cell sorter. Specifically, gates were set to sort GFP-negative cells as the 441 population of interest, as well as GFP-positive cells as a control population of cells still capable of 442 signaling. This screen was performed in duplicate. Genomic DNA was extracted from sorted cells 443 using the Zymo Quick gDNA micro prep kit. PCR was subsequently performed using barcoded 444 primers as previously described using the NEB Next High Fidelity 2x PCR master mix (92). PCR 445 bands were gel purified using the Thermo GeneJET gel extraction kit. Samples were then 446 sequenced via next-generation Illumina MiSeq using paired-end $150 \mathrm{bp}$ reads.

Screen Analysis

449 Raw MiSeq read files were aligned to the CRISPR SAM sgRNA library and raw reads for each 450 sgRNA were counted using the MAGeCK pipeline (29). sgRNA enrichment was determined using 451 the generated count files and the MAGeCK-MLE analysis pipeline. Genes were sorted based on 452 z-score and determined to be significantly enriched if their z-score was at least two standard 453 deviations above the average z-score of the entire sorted population.

\section{Western Blotting}

456 Cells were trypsinized and $1 \times 10^{6}$ cells were pelleted at $800 \mathrm{x}$ g for $5 \mathrm{~min}$. Equal amounts of cellular 457 material were loaded into 4-20\% acrylamide gels (Bio-Rad) and imaged using a ChemiDoc 458 Imaging System (Bio-Rad). Protein was transferred to a nitrocellulose membrane at $60 \mathrm{~V}$ for 60 
min. PBS with $5 \%(\mathrm{w} / \mathrm{v})$ non-fat dried milk and $0.1 \%$ Tween-20 were used to block for $1 \mathrm{~h}$ at $4{ }^{\circ} \mathrm{C}$.

460 Primary antibodies were then incubated with the membrane overnight at $4^{\circ} \mathrm{C}$. Antibodies used

461 were rabbit anti-ETV7 (Sigma, HPA029033), rabbit anti-IFIT1 (Cell Signaling, D2X9Z), mouse

462 anti-FLAG (Sigma, F3165) and mouse anti- $\alpha$ tubulin (Sigma, T5168). Membranes were washed

463 five times in PBS with 0.1\% Tween-20 and then an anti-rabbit-HRP (Thermo, A16104) or anti-

464 mouse-HRP (Thermo, A16072) secondary antibody was added for $1 \mathrm{~h}$. The membrane was then

465 washed five times and Clarity or Clarity Max ECL substrate (Bio-Rad) was added before being exposed to film and developed.

$R T-q P C R$

For all experiments except SARS-CoV-2 infection experiments, total RNA was collected and prepared using Monarch Total RNA Miniprep Kits (NEB). For SARS-CoV-2 experiments, cells

471 were collected in TRIzol (Invitrogen) and RNA was isolated using Phasemaker tubes (Invitrogen).

472 One-step RT-qPCR was performed with commercial TaqMan assays from Thermo for ETV7 473 (Hs00903229 m1), C1GALT1 (Hs00863329 g1), NUP153 (Hs01018919 m1), ISG15 474 (Hs00196051_m1), MX1 (Hs00895608_m1), IFIT1 (Hs00356631_g1), IFI44L 475 (Hs00915292_m1), RSAD2 (Hs00895608_m1), IFITM1 (Hs00705137_s1), OAS1 (Hs00973635_m1), IFIT2 (Hs00533665_m1), IFIT3 (Hs01922752_s1), IFI44 (Hs00197427_m1),

477 BST2 (Hs01561315_m1), and ACTB (Hs01060665_g1) and primers/probe from BEI targeting the 478 SARS-CoV-2 N region using the EXPRESS One-Step Superscript qRT-PCR Kit on an Applied 479 Biosystems StepOnePlus or QuantStudio 3 instrument. RNA was normalized using an endogenous 480 18S rRNA primer/probe set (Applied Biosystems). 
483 Nuclear extract from 293T cells expressing ETV7 and treated with IFN- $\alpha(100 \mathrm{U} / \mathrm{mL}, 9 \mathrm{~h})$ was

484 generated using NE-PER extraction reagents (Thermo Scientific). This nuclear extract was

485 incubated with poly(dI-dC) as nonspecific competitor DNA, 10x ligase buffer (Invitrogen), 200

486 mM EDTA, biotinylated DNA bait (either WT or -ETS ISG15 ISRE (93)), and 20x excess

487 nonbiotinylated DNA competitor for $30 \mathrm{~min}$ at room temperature. This mixture was then incubated

488 with streptavidin-coated magnetic beads (Invitrogen), followed by four washes with TTBS.

489 Proteins bound to the biotinylated DNA bait captured by the streptavidin beads were eluted with

490 protein sample buffer and then detected by Western blot. Input (nuclear extract) was diluted 1:200

491 for loading. No bait (control) contained no biotinylated DNA.

\section{$R N A$ sequencing}

494293 T cells were transfected with ETV7- or control-expressing plasmids and selected using 495 puromycin $(20 \mu \mathrm{g} / \mathrm{mL})$ for $24 \mathrm{~h}$ before treatment with IFN- $\alpha(100 \mathrm{U} / \mathrm{mL})$. Total RNA was 496 collected at $9 \mathrm{~h}$ post-IFN treatment using Monarch Total RNA Miniprep Kits (NEB). RNA was 497 prepped for RNA sequencing submission using the NEBNext Poly(A) mRNA Magnetic Isolation 498 Module (NEB), NEBNext Ultra II RNA Library Prep Kit for Illumina (NEB), and NEBNext 499 Multiplex Oligos for Illumina (NEB). Samples were analyzed on one lane of an Illumina HiSeq 5004000 using 50 bp single strand reads. Mapping of the raw reads to the human hg19 reference 501 genome was accomplished using a custom application on the Illumina BaseSpace Sequence Hub

502 (94). After data normalization, average read values were compared across samples. For 503 comparisons in which some samples had zero reads detected for a specific gene, one read was 504 added to all values in the sample to complete analyses that required non-zero values. The heat map 505 shows genes upregulated 2.5-fold (after normalization) with IFN treatment in the control samples. 506 Values shown are z-scores. 
$293 \mathrm{~T}$ cells were transfected with a FLAG-tagged ETV7-expressing plasmid, ETV7(FLAG), $48 \mathrm{~h}$

510 before treatment with IFN- $\alpha(100 \mathrm{U} / \mathrm{mL}, 9 \mathrm{~h})$. Chromatin immunoprecipitation was performed

511 using the ChIP-IT Express Enzymatic kit according to the manufacturer's directions (Active

512 Motif). DNA was enzymatically sheared for $10 \mathrm{~min}$. ChIP antibodies included mouse IgG (Active

513 Motif), rabbit anti-FLAG (Cell Signaling, 14793S), and mouse anti-FLAG (Sigma, F3165).

514 Quantitative PCR was performed using SYBR Green (Bio-Rad) and primers targeting the Chr12

515 gene desert (Active Motif) or IFI44L promoter (forward primer = 5',

516 TTTCATGCCTGCCTACATAC 3', reverse primer = 5' ATGCCAACTGCCACTAAC 3') in a

517 region containing two potential ISRE sequences overlapping with ETS sites, and analyzed using

518 the ChIP-IT qPCR Analysis kit (Active Motif).

Viruses

521 PR8-mNeon was generated via insertion of the mNeon fluorescent gene (95) into segment 4 of the

522 virus (48). Mal/04-mNeon was generated by inserting the mNeon fluorescent gene (95) into

523 segment 4 of the Mal/04 genome (49). Cal/09-sfGFP was generated via insertion of the sfGFP

524 gene (96) into segment 8 of the virus using the same scheme previously used to insert Cre 525 recombinase (97). Sendai-GFP was a gift from Benhur Lee (98). For influenza virus infections, 526 cells were either mock- or virus-infected for $1 \mathrm{~h}$ and then cultured in OptiMEM supplemented with 527 bovine serum albumin (BSA), penicillin-streptomycin, and $0.2 \mu \mathrm{g} / \mathrm{mL}$ TPCK-treated trypsin 528 protease (Sigma). For Sendai infections, cells were infected for $1 \mathrm{~h}$ and then cultured in DMEM. 529 For SARS-CoV-2 infections, cells were washed with PBS before infection with SARS-CoV5302 isolate USA-WA1/2020 from BEI Resources in 2\% FBS DMEM infection media for 1 hour. 531 PR8 WT, PR8-mNeon, Cal/09-sfGFP, Sendai-GFP, and SARS-CoV-2 were incubated at $37^{\circ} \mathrm{C}$, $532 \mathrm{Mal} / 04-\mathrm{mNeon}$ was incubated at $33^{\circ} \mathrm{C}$. 
534 Viral Growth Assays

535 Hemagglutination (HA) assays to measure the number of viral particles were performed by diluting 536 influenza infected cell supernatants collected at the indicated time points in cold PBS. An equal 537 amount of chicken blood diluted 1:40 in PBS was mixed with serially diluted virus and incubated 538 at $4{ }^{\circ} \mathrm{C}$ for $2-3 \mathrm{~h}$ before scoring. Infectious viral titers were determined using standard plaque assay 539 procedures on MDCK cells. Infected cell supernatants were collected at $18 \mathrm{~h}$, serially diluted, and 540 used to infect confluent 6-well plates for $1 \mathrm{~h}$ before removing the virus and adding the agar overlay.

541 Cells were then incubated at $37^{\circ} \mathrm{C}$ for $48 \mathrm{~h}$ before being fixed in $4 \%$ PFA overnight. The $4 \%$ PFA 542 was then aspirated, and the agar layer was removed before washing cells with PBS. Serum from 543 WT PR8 infected mice was diluted 1:2,000 in antibody dilution buffer $(5 \%(\mathrm{w} / \mathrm{v})$ non-fat dried 544 milk and $0.05 \%$ Tween-20 in PBS) and incubated on cells at $4{ }^{\circ} \mathrm{C}$ overnight. Cells were then 545 washed twice with PBS and incubated for $1 \mathrm{~h}$ with anti-mouse IgG horseradish peroxidase (HRP)546 conjugated sheep antibody (GE Healthcare) diluted 1:4,000 in antibody dilution buffer. Assays 547 were then washed twice with PBS and exposed to $0.5 \mathrm{~mL}$ of TrueBlue peroxidase substrate (KPL) 548 for $20 \mathrm{~min}$. Plates were then washed with water and dried before plaques were counted. 


\section{Supplementary Materials}

Fig. S1. CRISPR activation screen hit identification and validation.

Fig. S2. ETV7 represses IFN-stimulated expression and directly binds an ISG promoter.

Fig. S3. ETV7 loss increases IFN-stimulated expression.

Fig. S4. ETV7 loss results in decreased viral titers and increased antiviral gene expression.

Table S1. Hits from CRISPRa screen for negative regulators of the type I IFN response.

Table S2. ISRE sequences identified in the literature.

Table S3. Gene set enrichment analysis of 200 most downregulated genes in ETV7expressing cells without IFN treatment.

Table S4. Gene set enrichment analysis of 200 most downregulated genes in ETV7expressing cells after $9 \mathrm{hr}$ IFN treatment.

Data file S1. CRISPRa screen for negative regulators of the type I IFN response sgRNA sequences, transduction read counts, and screen read counts.

Data file S2. CRISPRa screen for negative regulators of the type I IFN response MAGeCK z-scores and potential hit cutoffs.

Data file S3. RNA sequencing with ETV7 overexpression and IFN treatment reads and results. 


\section{References}

1. W. M. Schneider, M. D. Chevillotte, C. M. Rice, Interferon-Stimulated Genes: A Complex Web of Host Defenses. Annu. Rev. Immunol. 32, 513-545 (2014).

2. J. W. Schoggins, Interferon-Stimulated Genes: What Do They All Do? Annu. Rev. Virol. 6, 567-584 (2019).

3. J. W. Schoggins, S. J. Wilson, M. Panis, M. Y. Murphy, C. T. Jones, P. Bieniasz, C. M. Rice, A diverse range of gene products are effectors of the type I interferon antiviral response. Nature. 472, 481-485 (2011).

4. J. W. Schoggins, D. A. MacDuff, N. Imanaka, M. D. Gainey, B. Shrestha, J. L. Eitson, K. B. Mar, R. B. Richardson, A. V. Ratushny, V. Litvak, R. Dabelic, B. Manicassamy, J. D. Aitchison, A. Aderem, R. M. Elliott, A. García-Sastre, V. Racaniello, E. J. Snijder, W. M. Yokoyama, M. S. Diamond, H. W. Virgin, C. M. Rice, Pan-viral specificity of IFNinduced genes reveals new roles for cGAS in innate immunity. Nature. 505, 691-695 (2014).

5. M. Kane, T. M. Zang, S. J. Rihn, C. M. Rice, S. J. Wilson, P. D. Bieniasz, Identification of Interferon-Stimulated Genes with Antiretroviral Activity. Cell Host Microbe. 20, 392405 (2016).

6. E. V. Mesev, R. A. LeDesma, A. Ploss, Decoding type I and III interferon signalling during viral infection. Nat. Microbiol. 4, 914-924 (2019).

7. B. X. Wang, E. N. Fish, The yin and yang of viruses and interferons. Trends Immunol. 33 (2012), doi:10.1016/j.it.2012.01.004.

8. G. R. Stark, J. E. Darnell, The JAK-STAT Pathway at Twenty. Immunity. 36, 503-514 (2012).

9. K. Honda, H. Yanai, A. Takaoka, T. Taniguchi, Regulation of the type I IFN induction: a current view. Int. Immunol. 17, 1367-1378 (2005).

10. D. E. Levy, D. S. Kessler, R. Pine, N. Reich, J. E. Darnell, Interferon-induced nuclear factors that bind a shared promoter element correlate with positive and negative transcriptional control. Genes Dev. 2, 383-93 (1988).

11. N. P. D. Liau, A. Laktyushin, I. S. Lucet, J. M. Murphy, S. Yao, E. Whitlock, K. Callaghan, N. A. Nicola, N. J. Kershaw, J. J. Babon, The molecular basis of JAK/STAT inhibition by SOCS1. Nat. Commun. 9, 1558 (2018).

12. M. P. Malakhov, O. A. Malakhova, K. Il Kim, K. J. Ritchie, D.-E. Zhang, UBP43 (USP18) specifically removes ISG15 from conjugated proteins. J. Biol. Chem. 277, 997681 (2002).

13. K.-I. Arimoto, S. Miyauchi, S. A. Stoner, J.-B. Fan, D.-E. Zhang, Negative regulation of type I IFN signaling. J. Leukoc. Biol. 103, 1099-1116 (2018).

14. G. Randall, L. Chen, M. Panis, A. K. Fischer, B. D. Lindenbach, J. Sun, J. Heathcote, C. M. Rice, A. M. Edwards, I. D. McGilvray, Silencing of USP18 Potentiates the Antiviral Activity of Interferon Against Hepatitis C Virus Infection. Gastroenterology. 131, 15841591 (2006).

15. K. G. Frey, C. M. I. Ahmed, R. Dabelic, L. D. Jager, E. N. Noon-Song, S. M. Haider, H. M. Johnson, N. J. Bigley, HSV-1-induced SOCS-1 expression in keratinocytes: use of a SOCS-1 antagonist to block a novel mechanism of viral immune evasion. J. Immunol. 183, 1253-62 (2009).

16. C. J. Carbone, H. Zheng, S. Bhattacharya, J. R. Lewis, A. M. Reiter, P. Henthorn, Z.-Y. Zhang, D. P. Baker, R. Ukkiramapandian, K. K. Bence, S. Y. Fuchs, Protein tyrosine phosphatase $1 \mathrm{~B}$ is a key regulator of IFNAR1 endocytosis and a target for antiviral therapies. Proc. Natl. Acad. Sci. U. S. A. 109, 19226-31 (2012). 
17. M. Sa Ribero, N. Jouvenet, M. Dreux, S. Nisole, Interplay between SARS-CoV-2 and the type I interferon response. PLOS Pathog. 16, e1008737 (2020).

18. J. R. Teijaro, S. Studer, N. Leaf, W. B. Kiosses, N. Nguyen, K. Matsuki, H. Negishi, T. Taniguchi, M. B. A. Oldstone, H. Rosen, S1PR1-mediated IFNAR1 degradation modulates plasmacytoid dendritic cell interferon- $\alpha$ autoamplification. Proc. Natl. Acad. Sci. U. S. A. 113, 1351-6 (2016).

19. K. B. Walsh, J. R. Teijaro, P. R. Wilker, A. Jatzek, D. M. Fremgen, S. C. Das, T. Watanabe, M. Hatta, K. Shinya, M. Suresh, Y. Kawaoka, H. Rosen, M. B. A. Oldstone, Suppression of cytokine storm with a sphingosine analog provides protection against pathogenic influenza virus. Proc. Natl. Acad. Sci. U. S. A. 108, 12018-23 (2011).

20. F. Naz, M. Arish, Battling COVID-19 Pandemic: Sphingosine-1-Phosphate Analogs as an Adjunctive Therapy? Front. Immunol. 11, 1102 (2020).

21. P. J. Hertzog, B. R. G. Williams, Fine tuning type I interferon responses. Cytokine Growth Factor Rev. 24, 217-225 (2013).

22. J. P. B. Viola, R. P. Donnelly, H. M. Johnson, H. A. R. Bluyssen, A. Michalska, K. Blaszczyk, J. Wesoly, A Positive Feedback Amplifier Circuit That Regulates Interferon (IFN)-Stimulated Gene Expression and Controls Type I and Type II IFN Responses. 9, 28 (2018).

23. N. Tanaka, T. Kawakami, T. Taniguchi, Recognition DNA sequences of interferon regulatory factor 1 (IRF-1) and IRF-2, regulators of cell growth and the interferon system. Mol. Cell. Biol. 13, 4531-8 (1993).

24. M. Sato, N. Hata, M. Asagiri, T. Nakaya, T. Taniguchi, N. Tanaka, Positive feedback regulation of type I IFN genes by the IFN-inducible transcription factor IRF-7. FEBS Lett. 441, 106-110 (1998).

25. L. L. Seifert, C. Si, D. Saha, M. Sadic, M. de Vries, S. Ballentine, A. Briley, G. Wang, A. M. Valero-Jimenez, A. Mohamed, U. Schaefer, H. M. Moulton, A. García-Sastre, S. Tripathi, B. R. Rosenberg, M. Dittmann, The ETS transcription factor ELF1 regulates a broadly antiviral program distinct from the type I interferon response. PLOS Pathog. 15, e1007634 (2019).

26. P. Hubel, C. Urban, V. Bergant, W. M. Schneider, B. Knauer, A. Stukalov, P. Scaturro, A. Mann, L. Brunotte, H. H. Hoffmann, J. W. Schoggins, M. Schwemmle, M. Mann, C. M. Rice, A. Pichlmair, A protein-interaction network of interferon-stimulated genes extends the innate immune system landscape. Nat. Immunol. 20, 493-502 (2019).

27. X. Li, X. Zhao, Y. Fang, X. Jiang, T. Duong, C. Fan, C.-C. Huang, S. R. Kain, Generation of Destabilized Green Fluorescent Protein as a Transcription Reporter. J. Biol. Chem. 273, 34970-34975 (1998).

28. S. Konermann, M. D. Brigham, A. E. Trevino, J. Joung, O. O. Abudayyeh, C. Barcena, P. D. Hsu, N. Habib, J. S. Gootenberg, H. Nishimasu, O. Nureki, F. Zhang, Genome-scale transcriptional activation by an engineered CRISPR-Cas9 complex. Nature. 517, 583-8 (2015).

29. W. Li, H. Xu, T. Xiao, L. Cong, M. I. Love, F. Zhang, R. A. Irizarry, J. S. Liu, M. Brown, X. S. Liu, MAGeCK enables robust identification of essential genes from genome-scale CRISPR/Cas9 knockout screens. Genome Biol. 15, 554 (2014).

30. I. Rusinova, S. Forster, S. Yu, A. Kannan, M. Masse, H. Cumming, R. Chapman, P. J. Hertzog, INTERFEROME v2.0: an updated database of annotated interferon-regulated genes. Nucleic Acids Res. 41, D1040-D1046 (2012).

31. A.-P. Han, C. Yu, L. Lu, Y. Fujiwara, C. Browne, G. Chin, M. Fleming, P. Leboulch, S. H. Orkin, J. Chen, Heme-regulated eIF2alpha kinase (HRI) is required for translational regulation and survival of erythroid precursors in iron deficiency. EMBO J. 20, 6909- 
6918 (2001).

32. A. Marg, Y. Shan, T. Meyer, T. Meissner, M. Brandenburg, U. Vinkemeier, Nucleocytoplasmic shuttling by nucleoporins Nup153 and Nup214 and CRM1-dependent nuclear export control the subcellular distribution of latent Stat1. J. Cell Biol. 165, 823-33 (2004).

33. M. D. Potter, A. Buijs, B. Kreider, L. van Rompaey, G. C. Grosveld, Identification and characterization of a new human ETS-family transcription factor, TEL2, that is expressed in hematopoietic tissues and can associate with TEL1/ETV6. Blood. 95, 3341-8 (2000).

34. H. Poirel, R. G. Lopez, V. Lacronique, V. Della Valle, M. Mauchauffé, R. Berger, J. Ghysdael, O. A. Bernard, Characterization of a novel ETS gene, TELB, encoding a protein structurally and functionaly related to TEL. Oncogene. 19, 4802-4806 (2000).

35. F. C. Harwood, R. I. Klein Geltink, B. P. O’Hara, M. Cardone, L. Janke, D. Finkelstein, I. Entin, L. Paul, P. J. Houghton, G. C. Grosveld, ETV7 is an essential component of a rapamycin-insensitive mTOR complex in cancer. Sci. Adv. 4, eaar3938 (2018).

40. D. J. Morales, D. J. Lenschow, The antiviral activities of ISG15. J. Mol. Biol. 425, 4995-

36. H. Wei, G. Badis, M. F. Berger, T. Kivioja, K. Palin, M. Enge, M. Bonke, A. Jolma, M. Varjosalo, A. R. Gehrke, J. Yan, S. Talukder, M. Turunen, M. Taipale, H. G. Stunnenberg, E. Ukkonen, T. R. Hughes, M. L. Bulyk, J. Taipale, Genome-wide analysis of ETS-family DNA-binding in vitro and in vivo. EMBO J. 29, 2147-2160 (2010).

37. J. Reimand, T. Arak, P. Adler, L. Kolberg, S. Reisberg, H. Peterson, J. Vilo, g:Profiler-a web server for functional interpretation of gene lists (2016 update). Nucleic Acids Res. 44, W83-W89 (2016).

38. N. E. Sanjana, O. Shalem, F. Zhang, Improved vectors and genome-wide libraries for CRISPR screening. Nat. Methods. 11, 783-784 (2014).

39. D. C. Busse, D. Habgood-Coote, S. Clare, C. Brandt, I. Bassano, M. Kaforou, M. Levin, J.-F. Eleouet, P. Kellam, J. S. Tregoning, Interferon-induced Protein-44 and Interferoninduced Protein 44-like restrict 1 replication of Respiratory Syncytial Virus 2 Downloaded from. J. Virol (2020), doi:10.1128/JVI.00297-20.

41. J. W. Schoggins, Recent advances in antiviral interferon-stimulated gene biology. F1000Research. 7, 309 (2018).

42. A. García-Sastre, Induction and evasion of type I interferon responses by influenza viruses. Virus Res. 162, 12-18 (2011).

43. A. L. Brass, I.-C. Huang, Y. Benita, S. P. John, M. N. Krishnan, E. M. Feeley, B. J. Ryan, J. L. Weyer, L. van der Weyden, E. Fikrig, D. J. Adams, R. J. Xavier, M. Farzan, S. J. Elledge, The IFITM Proteins Mediate Cellular Resistance to Influenza A H1N1 Virus, West Nile Virus, and Dengue Virus. Cell. 139, 1243-1254 (2009).

44. Y. Li, S. Banerjee, Y. Wang, S. A. Goldstein, B. Dong, C. Gaughan, R. H. Silverman, S. R. Weiss, Activation of RNase L is dependent on OAS3 expression during infection with diverse human viruses. Proc. Natl. Acad. Sci. U. S. A. 113, 2241-6 (2016).

45. A. Pichlmair, C. Lassnig, C.-A. Eberle, M. W. Górna, C. L. Baumann, T. R. Burkard, T. Bürckstümmer, A. Stefanovic, S. Krieger, K. L. Bennett, T. Rülicke, F. Weber, J. Colinge, M. Müller, G. Superti-Furga, IFIT1 is an antiviral protein that recognizes 5'-triphosphate RNA. Nat. Immunol. 12, 624-630 (2011).

46. M. A. Yondola, F. Fernandes, A. Belicha-Villanueva, M. Uccelini, Q. Gao, C. Carter, P. Palese, Budding capability of the influenza virus neuraminidase can be modulated by tetherin. J. Virol. 85, 2480-91 (2011).

47. X. Wang, E. R. Hinson, P. Cresswell, The Interferon-Inducible Protein Viperin Inhibits Influenza Virus Release by Perturbing Lipid Rafts. Cell Host Microbe. 2, 96-105 (2007). 
48. A. T. Harding, B. E. Heaton, R. E. Dumm, N. S. Heaton, Rationally Designed Influenza Virus Vaccines That Are Antigenically Stable during Growth in Eggs. MBio. 8 (2017), doi:10.1128/mBio.00669-17.

49. R. E. Dumm, J. K. Fiege, B. M. Waring, C. T. Kuo, R. A. Langlois, N. S. Heaton, Nonlytic clearance of influenza B virus from infected cells preserves epithelial barrier function. Nat. Commun. 10, 779 (2019).

50. J. R. Bedsaul, L. A. Zaritsky, K. C. Zoon, Type I interferon-mediated induction of antiviral genes and proteins fails to protect cells from the cytopathic effects of sendai virus infection. J. Interf. Cytokine Res. 36, 652-665 (2016).

51. J. M. Perreira, C. R. Chin, E. M. Feeley, A. L. Brass, IFITMs restrict the replication of multiple pathogenic viruses. J. Mol. Biol. 425 (2013), pp. 4937-4955.

52. D. F. Young, J. Andrejeva, X. Li, F. Inesta-Vaquera, C. Dong, V. H. Cowling, S. Goodbourn, R. E. Randall, Human IFIT1 Inhibits mRNA Translation of Rubulaviruses but Not Other Members of the Paramyxoviridae Family. J. Virol. 90, 9446-9456 (2016).

53. C. Bampi, L. Rasga, L. Roux, Antagonism to human BST-2/tetherin by Sendai virus glycoproteins. J. Gen. Virol. 94, 1211-9 (2013).

54. M. P. Manns, H. Wedemeyer, M. Cornberg, Treating viral hepatitis C: efficacy, side effects, and complications. Gut. 55, 1350-9 (2006).

55. E. Haasbach, K. Droebner, A. B. Vogel, O. Planz, Low-dose interferon Type I treatment is effective against $\mathrm{H} 5 \mathrm{~N} 1$ and swine-origin $\mathrm{H} 1 \mathrm{~N} 1$ influenza A viruses in vitro and in vivo. $J$. Interferon Cytokine Res. 31, 515-25 (2011).

56. M. R. Loutfy, L. M. Blatt, K. A. Siminovitch, S. Ward, B. Wolff, H. Lho, D. H. Pham, H. Deif, E. A. LaMere, M. Chang, K. C. Kain, G. A. Farcas, P. Ferguson, M. Latchford, G. Levy, J. W. Dennis, E. K. Y. Lai, E. N. Fish, Interferon Alfacon-1 Plus Corticosteroids in Severe Acute Respiratory Syndrome. JAMA. 290, 3222 (2003).

57. M. K. Konde, D. P. Baker, F. A. Traore, M. S. Sow, A. Camara, A. A. Barry, D. Mara, A. Barry, M. Cone, I. Kaba, A. A. Richard, A. H. Beavogui, S. Günther, on behalf of E. M. L. European Mobile Laboratory Consortium, M. Pintilie, E. N. Fish, Interferon $\beta$ - 1 a for the treatment of Ebola virus disease: A historically controlled, single-arm proof-ofconcept trial. PLoS One. 12, e0169255 (2017).

58. Q. Zhou, V. Chen, C. P. Shannon, X.-S. Wei, X. Xiang, X. Wang, Z.-H. Wang, S. J. Tebbutt, T. R. Kollmann, E. N. Fish, Interferon- $\alpha 2$ b Treatment for COVID-19. Front. Immunol. 11, 1061 (2020).

59. E. Davoudi-Monfared, H. Rahmani, H. Khalili, M. Hajiabdolbaghi, M. Salehi, L. Abbasian, H. Kazemzadeh, M. S. Yekaninejad, Efficacy and safety of interferon $\beta$ - $1 \mathrm{a}$ in treatment of severe COVID-19: A randomized clinical trial. Antimicrob. Agents Chemother. (2020), doi:10.1128/AAC.01061-20.

60. I. F.-N. Hung, K.-C. Lung, E. Y.-K. Tso, R. Liu, T. W.-H. Chung, M.-Y. Chu, Y.-Y. Ng, J. Lo, J. Chan, A. R. Tam, H.-P. Shum, V. Chan, A. K.-L. Wu, K.-M. Sin, W.-S. Leung, W.-L. Law, D. C. Lung, S. Sin, P. Yeung, C. C.-Y. Yip, R. R. Zhang, A. Y.-F. Fung, E. Y.-W. Yan, K.-H. Leung, J. D. Ip, A. W.-H. Chu, W.-M. Chan, A. C.-K. Ng, R. Lee, K. Fung, A. Yeung, T.-C. Wu, J. W.-M. Chan, W.-W. Yan, W.-M. Chan, J. F.-W. Chan, A. K.-W. Lie, O. T.-Y. Tsang, V. C.-C. Cheng, T.-L. Que, C.-S. Lau, K.-H. Chan, K. K.-W. To, K.-Y. Yuen, Triple combination of interferon beta-1b, lopinavir-ritonavir, and ribavirin in the treatment of patients admitted to hospital with COVID-19: an open-label, randomised, phase 2 trial. Lancet (London, England). 395, 1695-1704 (2020).

61. D. Blanco-Melo, B. E. Nilsson-Payant, W. C. Liu, S. Uhl, D. Hoagland, R. Møller, T. X. Jordan, K. Oishi, M. Panis, D. Sachs, T. T. Wang, R. E. Schwartz, J. K. Lim, R. A. Albrecht, B. R. tenOever, Imbalanced Host Response to SARS-CoV-2 Drives 
Development of COVID-19. Cell. 181, 1036-1045.e9 (2020).

62. H. Chu, J. F.-W. Chan, Y. Wang, T. T.-T. Yuen, Y. Chai, Y. Hou, H. Shuai, D. Yang, B. Chan, A. J. Zhang, K.-Y. Sit, W.-K. Au, K.-Y. Yuen, Comparative Replication and Immune Activation Profiles of SARS-CoV-2 and SARS-CoV in Human Lungs: An Ex Vivo Study With Implications for the Pathogenesis of COVID-19. Clin. Infect. Dis. (2020), doi:10.1093/cid/ciaa410.

63. J. Hadjadj, N. Yatim, L. Barnabei, A. Corneau, J. Boussier, N. Smith, H. Péré, B. Charbit, V. Bondet, C. Chenevier-Gobeaux, P. Breillat, N. Carlier, R. Gauzit, C. Morbieu, F. Pène, N. Marin, N. Roche, T.-A. Szwebel, S. H. Merkling, J.-M. Treluyer, D. Veyer, L. Mouthon, C. Blanc, P.-L. Tharaux, F. Rozenberg, A. Fischer, D. Duffy, F. Rieux-Laucat, S. Kernéis, B. Terrier, Impaired type I interferon activity and inflammatory responses in severe COVID-19 patients. Science (2020), doi:10.1126/science.abc6027.

64. A. Vanderheiden, P. Ralfs, T. Chirkova, A. A. Upadhyay, M. G. Zimmerman, S. Bedoya, H. Aoued, G. M. Tharp, K. L. Pellegrini, C. Manfredi, E. Sorscher, B. Mainou, J. E. Kohlmeier, A. C. Lowen, P.-Y. Shi, V. D. Menachery, L. J. Anderson, A. Grakoui, S. E. Bosinger, M. S. Suthar, Type I and Type III IFN Restrict SARS-CoV-2 Infection of Human Airway Epithelial 1 Cultures 23 Downloaded from. J. Virol (2020), doi:10.1128/JVI.00985-20.

65. K. G. Lokugamage, A. Hage, M. de Vries, A. M. Valero-Jimenez, C. Schindewolf, M. Dittmann, R. Rajsbaum, V. D. Menachery, bioRxiv, in press, doi:10.1101/2020.03.07.982264.

66. E. Mantlo, N. Bukreyeva, J. Maruyama, S. Paessler, C. Huang, Antiviral activities of type I interferons to SARS-CoV-2 infection. Antiviral Res. 179, 104811 (2020).

67. S. Pfaender, K. B. Mar, E. Michailidis, A. Kratzel, I. N. Boys, P. V'kovski, W. Fan, J. N. Kelly, D. Hirt, N. Ebert, H. Stalder, H. Kleine-Weber, M. Hoffmann, H. Heinrich Hoffmann, M. Saeed, R. Dijkman, E. Steinmann, M. Wight-Carter, M. B. McDougal, N. W. Hanners, S. Pöhlmann, T. Gallagher, D. Todt, G. Zimmer, C. M. Rice, J. W. Schoggins, V. Thiel, LY6E impairs coronavirus fusion and confers immune control of viral disease. Nat. Microbiol., 1-10 (2020).

68. X. Zhao, S. Zheng, D. Chen, M. Zheng, X. Li, G. Li, H. Lin, J. Chang, H. Zeng, J.-T. Guo, LY6E Restricts the Entry of Human Coronaviruses, Including the Currently Pandemic SARS-CoV-2. J. Virol. (2020), doi:10.1128/JVI.00562-20.

69. R. Li, H. Pei, D. K. Watson, Regulation of Ets function by protein-protein interactions. Oncogene. 19, 6514-6523 (2000).

70. A. D. Sharrocks, The ETS-domain transcription factor family. Nat. Rev. Mol. Cell Biol. 2, 827-837 (2001).

71. D. Meraro, M. Gleit-Kielmanowicz, H. Hauser, B.-Z. Levi, IFN-Stimulated Gene 15 Is Synergistically Activated Through Interactions Between the Myelocyte/LymphocyteSpecific Transcription Factors, PU.1, IFN Regulatory Factor-8/IFN Consensus Sequence Binding Protein, and IFN Regulatory Factor-4: Characterization o. J. Immunol. 168, 6224-6231 (2002).

72. T. Taniguchi, K. Ogasawara, A. Takaoka, N. Tanaka, IRF Family of Transcription Factors as Regulators of Host Defense. Annu. Rev. Immunol. 19, 623-655 (2001).

73. A. L. Brass, E. Kehrli, C. F. Eisenbeis, U. Storb, H. Singh, Pip, a lymphoid-restricted IRF, contains a regulatory domain that is important for autoinhibition and ternary complex formation with the Ets factor PU.1. Genes Dev. 10, 2335-2347 (1996).

74. W. Wang, L. Xu, J. Su, M. P. Peppelenbosch, Q. Pan, Transcriptional Regulation of Antiviral Interferon-Stimulated Genes. Trends Microbiol. 25, 573-584 (2017). 
75. T.-Y. Liu, T. Burke, L. P. Park, C. W. Woods, A. K. Zaas, G. S. Ginsburg, A. O. Hero, An individualized predictor of health and disease using paired reference and target samples. BMC Bioinformatics. 17, 47 (2016).

76. P. C. De La Cruz-Rivera, M. Kanchwala, H. Liang, A. Kumar, L.-F. Wang, C. Xing, J. W. Schoggins, The IFN Response in Bats Displays Distinctive IFN-Stimulated Gene Expression Kinetics with Atypical RNASEL Induction. J. Immunol. 200, 209-217 (2018).

77. K. Haq, J. T. Brisbin, N. Thanthrige-Don, M. Heidari, S. Sharif, Transcriptome and proteome profiling of host responses to Marek's disease virus in chickens. Vet. Immunol. Immunopathol. 138, 292-302 (2010).

78. H. Kawagoe, M. Potter, J. Ellis, G. C. Grosveld, TEL2, an ETS factor expressed in human leukemia, regulates monocytic differentiation of U937 cells and blocks the inhibitory effect of TEL1 on Ras-induced cellular transformation. Cancer Res. 64, 6091-6100 (2004).

79. P. Rasighaemi, A. C. Ward, ETV6 and ETV7: Siblings in hematopoiesis and its disruption in disease. Crit. Rev. Oncol. Hematol. 116, 106-115 (2017).

80. J. A. Nick, S. M. Caceres, J. E. Kret, K. R. Poch, M. Strand, A. V. Faino, D. P. Nichols, M. T. Saavedra, J. L. Taylor-Cousar, M. W. Geraci, E. L. Burnham, M. B. Fessler, B. T. Suratt, E. Abraham, M. Moss, K. C. Malcolm, Extremes of Interferon-Stimulated Gene Expression Associate with Worse Outcomes in the Acute Respiratory Distress Syndrome. PLoS One. 11, e0162490 (2016).

81. Y. Muramoto, J. E. Shoemaker, M. Q. Le, Y. Itoh, D. Tamura, Y. Sakai-Tagawa, H. Imai, R. Uraki, R. Takano, E. Kawakami, M. Ito, K. Okamoto, H. Ishigaki, H. Mimuro, C. Sasakawa, Y. Matsuoka, T. Noda, S. Fukuyama, K. Ogasawara, H. Kitano, Y. Kawaoka, Disease severity is associated with differential gene expression at the early and late phases of infection in nonhuman primates infected with different $\mathrm{H} 5 \mathrm{~N} 1$ highly pathogenic avian influenza viruses. J. Virol. 88, 8981-97 (2014).

82. S. Davidson, M. K. Maini, A. Wack, Disease-promoting effects of type I interferons in viral, bacterial, and coinfections. J. Interferon Cytokine Res. 35, 252-64 (2015).

83. M. E. C. Meuwissen, R. Schot, S. Buta, G. Oudesluijs, S. Tinschert, S. D. Speer, Z. Li, L. van Unen, D. Heijsman, T. Goldmann, M. H. Lequin, J. M. Kros, W. Stam, M. Hermann, R. Willemsen, R. W. W. Brouwer, W. F. J. Van IJcken, M. Martin-Fernandez, I. de Coo, J. Dudink, F. A. T. de Vries, A. Bertoli Avella, M. Prinz, Y. J. Crow, F. W. Verheijen, S. Pellegrini, D. Bogunovic, G. M. S. Mancini, Human USP18 deficiency underlies type 1 interferonopathy leading to severe pseudo-TORCH syndrome. J. Exp. Med. 213, 1163-74 (2016).

84. J.-C. Marine, D. J. Topham, C. McKay, D. Wang, E. Parganas, D. Stravopodis, A. Yoshimura, J. N. Ihle, SOCS1 Deficiency Causes a Lymphocyte-Dependent Perinatal Lethality. Cell. 98, 609-616 (1999).

85. W. S. Alexander, R. Starr, J. E. Fenner, C. L. Scott, E. Handman, N. S. Sprigg, J. E. Corbin, A. L. Cornish, R. Darwiche, C. M. Owczarek, T. W. Kay, N. A. Nicola, P. J. Hertzog, D. Metcalf, D. J. Hilton, SOCS1 Is a Critical Inhibitor of Interferon $\gamma$ Signaling and Prevents the Potentially Fatal Neonatal Actions of this Cytokine. Cell. 98, 597-608 (1999).

86. B. A. Croker, D. L. Krebs, J.-G. Zhang, S. Wormald, T. A. Willson, E. G. Stanley, L. Robb, C. J. Greenhalgh, I. Förster, B. E. Clausen, N. A. Nicola, D. Metcalf, D. J. Hilton, A. W. Roberts, W. S. Alexander, SOCS3 negatively regulates IL-6 signaling in vivo. Nat. Immunol. 4, 540-545 (2003).

87. K.-P. Knobeloch, O. Utermöhlen, A. Kisser, M. Prinz, I. Horak, Reexamination of the Role of Ubiquitin-Like Modifier ISG15 in the Phenotype of UBP43-Deficient Mice 
Downloaded from. Mol. Cell. Biol. 25, 11030-11034 (2005).

88. Y. Okada, D. Wu, G. Trynka, T. Raj, C. Terao, K. Ikari, Y. Kochi, K. Ohmura, A. Suzuki, S. Yoshida, R. R. Graham, A. Manoharan, W. Ortmann, T. Bhangale, J. C. Denny, R. J. Carroll, A. E. Eyler, J. D. Greenberg, J. M. Kremer, D. A. Pappas, L. Jiang, J. Yin, L. Ye, D.-F. Su, J. Yang, G. Xie, E. Keystone, H.-J. Westra, T. Esko, A. Metspalu, X. Zhou, N. Gupta, D. Mirel, E. A. Stahl, D. Diogo, J. Cui, K. Liao, M. H. Guo, K. Myouzen, T. Kawaguchi, M. J. H. Coenen, P. L. C. M. van Riel, M. A. F. J. van de Laar, H.-J. Guchelaar, T. W. J. Huizinga, P. Dieudé, X. Mariette, S. Louis Bridges Jr, A. Zhernakova, R. E. M. Toes, P. P. Tak, C. Miceli-Richard, S.-Y. Bang, H.-S. Lee, J. Martin, M. A. Gonzalez-Gay, L. Rodriguez-Rodriguez, S. Rantapää-Dahlqvist, L. Ärlestig, H. K. Choi, Y. Kamatani, P. Galan, M. Lathrop, S. Eyre, J. Bowes, A. Barton, N. de Vries, L. W. Moreland, L. A. Criswell, E. W. Karlson, A. Taniguchi, R. Yamada, M. Kubo, J. S. Liu, S.-C. Bae, J. Worthington, L. Padyukov, L. Klareskog, P. K. Gregersen, S. Raychaudhuri, B. E. Stranger, P. L. De Jager, L. Franke, P. M. Visscher, M. A. Brown, H. Yamanaka, T. Mimori, A. Takahashi, H. Xu, T. W. Behrens, K. A. Siminovitch, S. Momohara, F. Matsuda, K. Yamamoto, R. M. Plenge, K. Yamamoto, R. M. Plenge, Genetics of rheumatoid arthritis contributes to biology and drug discovery. Nature. 506, 376-381 (2014).

89. T. James, M. Lindén, H. Morikawa, S. J. Fernandes, S. Ruhrmann, M. Huss, M. Brandi, F.

90. J. E. Castañeda-Delgado, Y. Bastián-Hernandez, N. Macias-Segura, D. Santiago-Algarra, Piehl, M. Jagodic, J. Tegnér, M. Khademi, T. Olsson, D. Gomez-Cabrero, I. Kockum, Impact of genetic risk loci for multiple sclerosis on expression of proximal genes in patients. Hum. Mol. Genet. 27, 912-928 (2018).

J. D. Castillo-Ortiz, A. L. Alemán-Navarro, P. Martínez-Tejada, L. Enciso-Moreno, Y. Garcia-De Lira, D. Olguín-Calderón, L. A. Trouw, C. Ramos-Remus, J. A. EncisoMoreno, Type I Interferon Gene Response Is Increased in Early and Established Rheumatoid Arthritis and Correlates with Autoantibody Production. Front. Immunol. 8, 285 (2017).

91. A. Hundeshagen, M. Hecker, B. K. Paap, C. Angerstein, O. Kandulski, C. Fatum, C. Hartmann, D. Koczan, H.-J. Thiesen, U. Klaus Zettl, Elevated type I interferon-like activity in a subset of multiple sclerosis patients: molecular basis and clinical relevance. $J$. Neuroinflammation. 9, 574 (2012).

92. B. E. Heaton, E. M. Kennedy, R. E. Dumm, A. T. Harding, M. T. Sacco, D. Sachs, N. S. Heaton, A CRISPR Activation Screen Identifies a Pan-avian Influenza Virus Inhibitory Host Factor. Cell Rep. 20, 1503-1512 (2017).

93. S. Schmid, M. Mordstein, G. Kochs, A. García-Sastre, B. R. TenOever, Transcription factor redundancy ensures induction of the antiviral state. J. Biol. Chem. 285, 4201342022 (2010).

94. N. S. Heaton, R. A. Langlois, D. Sachs, J. K. Lim, P. Palese, R. Benjamin, Long-term survival of influenza virus infected club cells drives immunopathology. 211, 1707-1714 (2014).

95. N. C. Shaner, G. G. Lambert, A. Chammas, Y. Ni, P. J. Cranfill, M. A. Baird, B. R. Sell, J. R. Allen, R. N. Day, M. Israelsson, M. W. Davidson, J. Wang, A bright monomeric green fluorescent protein derived from Branchiostoma lanceolatum. Nat. Methods. 10, 407-9 (2013).

96. J.-D. Pédelacq, S. Cabantous, T. Tran, T. C. Terwilliger, G. S. Waldo, Engineering and characterization of a superfolder green fluorescent protein. Nat. Biotechnol. 24, 79-88 (2006). 
Heaton, DNA mismatch repair is required for the host innate response and controls cellular fate after influenza virus infection. Nat. Microbiol. 4, 1964-1977 (2019).

98. S. M. Beaty, A. Park, S. T. Won, P. Hong, M. Lyons, F. Vigant, A. N. Freiberg, B. R. tenOever, W. P. Duprex, B. Lee, Efficient and Robust Paramyxoviridae Reverse Genetics Systems. mSphere. 2 (2017), doi:10.1128/mSphere.00376-16.

99. C. T. Workman, Y. Yin, D. L. Corcoran, T. Ideker, G. D. Stormo, P. V. Benos, enoLOGOS: a versatile web tool for energy normalized sequence logos. Nucleic Acids Res. 33, W389-W392 (2005).

100. S. Babicki, D. Arndt, A. Marcu, Y. Liang, J. R. Grant, A. Maciejewski, D. S. Wishart, Heatmapper: web-enabled heat mapping for all. Nucleic Acids Res. 44, W147-W153 (2016).

101. H. A. R. Bluyssen, R. J. Vlietstra, P. W. Faber, E. M. E. Smit, A. Hagemeijer, J. Trapman, Structure, Chromosome Localization, and Regulation of Expression of the InterferonRegulated Mouse Ifi54/Ifi56 Gene Family. Genomics. 24, 137-148 (1994).

102. T. Ohtomo, Y. Sugamata, Y. Ozaki, K. Ono, Y. Yoshimura, S. Kawai, Y. Koishihara, S. Ozaki, M. Kosaka, T. Hirano, M. Tsuchiya, Molecular Cloning and Characterization of a Surface Antigen Preferentially Overexpressed on Multiple Myeloma Cells. Biochem. Biophys. Res. Commun. 258, 583-591 (1999).

103. W. Yang, J. Tan, R. Liu, X. Cui, Q. Ma, Y. Geng, W. Qiao, Interferon- $\gamma$ Upregulates Expression of IFP35 Gene in HeLa Cells via Interferon Regulatory Factor-1. PLoS One. 7 (2012), doi:10.1371/JOURNAL.PONE.0050932.

104. M. G. Wathelet, C. H. Lin, B. S. Parekh, L. V Ronco, P. M. Howley, T. Maniatis, Virus infection induces the assembly of coordinately activated transcription factors on the IFNbeta enhancer in vivo. Mol. Cell. 1, 507-18 (1998).

105. B. Testoni, V. Schinzari, F. Guerrieri, S. Gerbal-Chaloin, G. Blandino, M. Levrero, p53paralog DNp73 oncogene is repressed by IFNa/STAT2 through the recruitment of the Ezh2 polycomb group transcriptional repressor. Oncogene. 30, 2670-8 (2011).

106. M. N. Rutherford, G. E. Hannigan, B. R. Williams, Interferon-induced binding of nuclear factors to promoter elements of the 2-5A synthetase gene. EMBO J. 7, 751-9 (1988).

107. Q. Wang, G. Floyd-Smith, The p69/71 2-5A synthetase promoter contains multiple regulatory elements required for interferon- $\alpha$-induced expression. DNA Cell Biol. 16, 1385-1394 (1997).

108. D. Rebouillat, A. Hovnanian, G. David, A. G. Hovanessian, B. R. G. Williams, Characterization of the Gene Encoding the 100-kDa Form of Human 2',5'Oligoadenylate Synthetase. Genomics. 70, 232-240 (2000).

109. N. Wang, Q. Dong, J. Li, R. K. Jangra, M. Fan, A. R. Brasier, S. M. Lemon, L. M. Pfeffer, $\mathrm{K}$. Li, Viral induction of the zinc finger antiviral protein is IRF3-dependent but NFkappaB-independent. J. Biol. Chem. 285, 6080-90 (2010). 
961 Acknowledgements: We acknowledge assistance from Mike Cook and the Duke Cancer Institute

962 Flow Cytometry Core. We thank Robert Lefkowitz and his laboratory for assistance with and use

963 of the ChemiDoc Imaging System. We would like to thank Dr. Clare Smith for help establishing

964 SARS-CoV-2 viral infection assays at BSL3. We also thank Ephraim Tsalik, Micah McClain, and

965 Bandita Gershon for helpful discussions and Ben Chambers, Stacy Webb, and other members of

966 the Heaton lab for critical reading of the manuscript. Funding: Biocontainment work was

967 performed in the Duke Regional Biocontainment Laboratory under the direction of Greg

968 Sempowski, which received partial support for construction from the National Institutes of Health,

969 National Institute of Allergy and Infectious Diseases (UC6-AI058607). H.M.F. and A.T.H. were

970 supported by NIH training grant T32-CA009111. N.S.H. is supported by R01-HL142985, R01-

971 AI137031, and funding from the Defense Advanced Research Projects Agency's (DARPA)

972 PReemptive Expression of Protective Alleles and Response Elements (PREPARE) program

973 (Cooperative agreement \#HR00111920008). The views, opinions and/or findings expressed are

974 those of the author and should not be interpreted as representing the official views or policies of

975 the U.S. Government. Author contributions: H.M.F., A.T.H. and N.S.H. designed the study.

976 H.M.F., A.T.H., and B.E.H. performed experiments. H.M.F., A.T.H. and N.S.H. analyzed data.

977 H.M.F. and N.S.H. wrote the paper. Competing interests: The authors declare no competing

978 interests. Data and materials availability: All next generation sequencing data are available at

979 NCBI GEO under accession number GSE140718. The following reagent was deposited by the

980 Centers for Disease Control and Prevention and obtained through BEI Resources, NIAID, NIH:

981 SARS-Related Coronavirus 2, Isolate USA-WA1/2020, NR-52281.

982

983

984 